\title{
Gravity-wave effects on tracer gases and stratospheric aerosol concentrations during the 2013 ChArMEx campaign
}

\author{
Fabrice Chane Ming ${ }^{1}$, Damien Vignelles ${ }^{2}$, Fabrice Jegou ${ }^{2}$, Gwenael Berthet ${ }^{2}$, Jean-Baptiste Renard ${ }^{2}$, \\ François Gheusi ${ }^{3}$, and Yuriy Kuleshov ${ }^{4,5,6,7}$ \\ ${ }^{1}$ Université de la Réunion, Laboratoire de l'Atmosphère et des Cyclones, UMR8105, UMR CNRS-Météo France-Université, \\ La Réunion, France \\ ${ }^{2}$ CNRS, LPC2E, UMR 7328, CNRS/Université d'Orléans, Orléans, France \\ ${ }^{3}$ Laboratoire d'Aérologie, UMR5560, Université de Toulouse and CNRS, Toulouse, France \\ ${ }^{4}$ Bureau of Meteorology, Melbourne, Australia \\ ${ }^{5}$ School of Science, RMIT University, Melbourne, Australia \\ ${ }^{6}$ Faculty of Science, Engineering and Technology, Swinburne University, Melbourne, Australia \\ ${ }^{7}$ School of Mathematics and Statistics, Melbourne University, Melbourne, Australia
}

Correspondence to: Fabrice Chane Ming (fchane@univ-reunion.fr)

Received: 29 October 2015 - Published in Atmos. Chem. Phys. Discuss.: 3 February 2016

Revised: 24 May 2016 - Accepted: 3 June 2016 - Published: 1 July 2016

\begin{abstract}
Coupled balloon-borne observations of Light Optical Aerosol Counter (LOAC), M10 meteorological global positioning system (GPS) sondes, ozonesondes, and GPS radio occultation data, are examined to identify gravity-wave (GW)-induced fluctuations on tracer gases and on the vertical distribution of stratospheric aerosol concentrations during the 2013 ChArMEx (Chemistry-Aerosol Mediterranean Experiment) campaign. Observations reveal signatures of GWs with short vertical wavelengths less than $4 \mathrm{~km}$ in dynamical parameters and tracer constituents, which are also correlated with the presence of thin layers of strong local enhancements of aerosol concentrations in the upper troposphere and the lower stratosphere. In particular, this is evident from a case study above Ile du Levant $\left(43.02^{\circ} \mathrm{N}, 6.46^{\circ} \mathrm{E}\right)$ on 26-29 July 2013. Observations show a strong activity of dominant mesoscale inertia GWs with horizontal and vertical wavelengths of $370-510 \mathrm{~km}$ and $2-3 \mathrm{~km}$ respectively, and periods of $10-13 \mathrm{~h}$ propagating southward at altitudes of 13-20 km during 27-28 July. The European Centre for Medium-Range Weather Forecasts (ECMWF) analyses also show evidence of mesoscale inertia GWs with similar horizontal characteristics above the eastern part of France. Raytracing experiments indicate the jet-front system as the main source of observed GWs. Using a simplified linear GW theory, synthetic vertical profiles of dynamical parameters with
\end{abstract}

large stratospheric vertical wind maximum oscillations of $\pm 40 \mathrm{mms}^{-1}$ are produced for the dominant mesoscale $\mathrm{GW}$ observed at heights of $13-20 \mathrm{~km}$. Parcel advection method reveals signatures of GWs in the ozone mixing ratio and the tropospheric-specific humidity. Simulated vertical wind perturbations of the dominant GWs and small-scale perturbations of aerosol concentration (aerosol size of $0.2-0.7 \mu \mathrm{m}$ ) are revealed to be in phase in the lower stratosphere. Present results support the importance of vertical wind perturbations in the GW-aerosol relationship. Observed mesoscale GWs induce a strong modulation of the amplitude of tracer gases and the stratospheric aerosol background.

\section{Introduction}

Gravity waves (GWs) affect the dynamics of the middle atmosphere by momentum transport and momentum deposition, and mixing above the upper troposphere (UT), as well as chemistry and consequently have an impact on the global circulation and climate (Fritts and Alexander, 2003; Geller et al., 2013; Ern et al., 2014). Several previous studies reveal atmospheric waves to be important sources of stratospheric tracer variability. Analytical wave-tracer interaction models help to identify the nature of waves and to quantify ampli- 
tudes and effects of waves in the middle atmosphere from observations (Eckermann et al., 1998; Chane Ming et al., 2000; $\mathrm{Xu}$ et al., 2000). They are usually used to quantify perturbations induced by GWs on tracer constituents. Small-scale structures were misrepresented by past numerical models and therefore considered as meteorological noise. Thanks to recent progress in computer technologies, current operational numerical weather prediction models have sufficient spatial and temporal resolution to resolve the portion of the $\mathrm{GW}$ wave spectrum with horizontal wavelengths of $100-1000 \mathrm{~km}$ (Shutts and Vosper, 2011). However, global climate models as well as numerical weather prediction models still need a set of GW parameterisations with a large number of tunable parameters for a realistic representation of the middle atmosphere (Preusse et al., 2014). By comparison with observations, it has been shown that the resolved GWs are usually under represented (Schroeder et al., 2009). Thus, measuring constituent response using analytical wave-tracer interaction models remains an inexpensive alternative way to derive correct constituent backgrounds and wave-related quantities.

Aerosols play an important role in meteorology, in radiative processes, and in atmospheric chemistry in the free atmosphere (Hobbs, 1993). Stratospheric aerosols are important for a number of processes related to the chemical and radiation balance of the atmosphere and consequently they impact on climate and its variability (Deshler, 2008). Even during volcanically quiescent periods (Hamill et al., 1997; SPARC Report No. 4, 2006) when background stratospheric aerosol loading is low, aerosols may have reduced global warming effects (Solomon et al., 2011). During the process of formation and growth of atmospheric aerosols, the aerosol dynamics and atmospheric chemistry are also coupled with large- and small-scale meteorological dynamics. In the troposphere, for example, vertical wind shear can play a dominant role in aerosol-cloud interactions especially in regulating aerosol effects on the strength of isolated deep convective clouds (Fan et al., 2009). In the stratosphere, Hommel et al. (2015) described how tropical stratospheric aerosol is affected by the quasi-biennial oscillation. Vaughan et al. (1987) reported dynamical influences on the short-term variability of stratospheric aerosols from vertical profiles of aerosol backscatter ratio obtained by a high vertical resolution lidar $(30 \mathrm{~m})$ and $20 \mathrm{~min}$ integration time at Aberystwyth $\left(52.4^{\circ} \mathrm{N}, 4.1^{\circ} \mathrm{W}\right)$. Their observations reveal wave-like structures, which could be attributed to stratospheric GWs. Tropical waves with periods shorter than a day could also explain some variability in aerosol distribution observed in Indonesia (Matsumura et al., 2001). From a model study, Carslaw et al. (1999) concluded that mountain-induced mesoscale temperature perturbations may be an important source of nitric acid trihydrate particles in the Arctic. Bacmeister et al. (1999) analysed the impact of mesoscale temperature perturbations and heating-cooling rates due to a spectrum of stratospheric GWs on the growth and evaporation of stratospheric nitric acid trihydrate particles. Their microphysical trajectory-box model reveals significant scatter in aerosol volume around the thermodynamic equilibrium values as a result of temperature perturbations. Using a Lagrangianbased sectional box model, Nilsson et al. (2000) showed that the temperature amplitude of short-period waves is the most important wave characteristic controlling the mean nucleation rate and net particle number concentration of $0.5 \mathrm{~nm}-$ $1 \mu \mathrm{m}$ size classes. They also suggest that GWs could enhance the aerosol nucleation rate up to 5 orders of magnitude if the temperature perturbation due to the wave is as strong as $5 \mathrm{~K}$. In addition turbulent mixing and GWs are likely to promote the production of new aerosols (Zahn et al., 2000; SPARC Report No. 4, 2006). Thus, previous studies highlight lack of information on GW-aerosol interactions with measurements, especially to improve aerosol modelling.

This study analyses GW-induced small-scale variability on high vertical resolution measurements of tracer gases and stratospheric aerosols during the volcanically quiescent period of the 2013 Chemistry-Aerosol Mediterranean Experiment (ChArMEx) campaign. Methodology and several complementary analyses based on observations and modelling are described to detect and characterise GWs as well as GW sources. The method is fully illustrated based on a case study on 27 July 2013. Effects of GWs on tracer gases such as ozone and water vapour as well as GW-stratospheric aerosol relationship are investigated.

The paper is structured as follows. A description of the ChArMEx campaign and the data are presented in Sect. 2, and methodologies and analyses in Sect. 3. Section 4 describes the synoptic situation on 27 July 2013. Results of the case study on 27 July 2013 are discussed in Sect. 5. Conclusions are drawn in Sect. 6.

\section{ChArMEx campaign and data description}

The ChArMEx campaign (http://charmex.lsce.ipsl.fr) is part of the international and regional multidisciplinary initiative Mediterranean Integrated STudies at Regional And Local Scales (MISTRALS). It aims to improve the characterisation of short-lived ( $\leq 1$ month) particulate and gaseous tropospheric trace species responsible for atmospheric pollution over the Mediterranean Basin, and evaluating its impacts on the present and future state of the atmospheric environment. The campaign was carried out during the Northern Hemisphere summer from 10 June to 10 August 2013. In addition to ground-based observations, airborne operations were organised during two special observation periods (SOP1 and SOP2). The SOP1 from 12 June to 5 July was dedicated primarily to the study of interactions between aerosols and radiation balance and the second one from 23 July to 9 August to the study of chemical processes and more particularly to the formation of secondary aerosols.

The Light Optical Aerosol Counter (LOAC) is a light and compact optical counter, which has been designed 
to perform measurements of aerosols from the ground to the middle stratosphere (up to $37 \mathrm{~km}$ heights) carried by all types of balloons in various atmospheric conditions (Renard et al., 2016). During balloon ascent, it provides information on the concentration and size distribution of aerosols on 19 size classes from $0.2 \mu \mathrm{m}$ to $\sim 50 \mu \mathrm{m}$ in diameter every $10 \mathrm{~s}(\approx 50 \mathrm{~m}$ heights $)$, as well as the main nature of particles (carbonaceous aerosol, mineral, droplets of water, or sulfuric acid). The technique is based on the observation of the scattered light by particles at two angles (Lurton et al., 2014). The instrument can count up to $\sim 3000$ particles $\mathrm{cm}^{-3}$ smaller than $1 \mu \mathrm{m}$, about 20 particles $\mathrm{cm}^{-3}$ for particles larger than $1 \mu \mathrm{m}$ in dry conditions, and up to 200 particles $\mathrm{cm}^{-3}$ in fog/cloud conditions. For the LOAC integration time of $10 \mathrm{~s}$, the counting uncertainty at $1 \sigma$ is about $\pm 15 \%$ for concentrations greater than $10^{-1}$ particles $\mathrm{cm}^{-3}$. Renard et al. $(2015,2016)$ provided a detailed description of the instrument as well as information on calibration and validation of measurements with crosscomparisons with several instruments during several campaigns.

Electrochemical concentration cell (ECC) ozonesondes developed by Komhyr (1969) are the most commonly used worldwide for tropospheric and stratospheric ozone soundings (Smit et al., 2007; Smit, 2013). The measurement principle is based on the electric current of a few $\mu \mathrm{A}$ generated through the cell as consequence of oxidation of iodide ions by ozone contained in ambient air bubbling in a potassium iodide electrochemical solution. The typical response time to an ozone concentration step change is $20-30 \mathrm{~s}$, so that the practical vertical resolution for a balloon ascending at $5 \mathrm{~ms}^{-1}$ is around $100-150 \mathrm{~m}$, even though ozone data are provided every second. The ozone measurement accuracy is within $5 \%$ in the stratosphere but is worse in the troposphere, around $10 \%$, owing to lower ambient ozone concentrations.

Nineteen LOAC sondes and fifteen ECC ozonesondes were launched using meteorological balloons during ChArMEx in summer 2013, from Minorca Island $\left(39.99^{\circ} \mathrm{N}\right.$, $\left.4.25^{\circ} \mathrm{E}\right)$ in Spain during SOP1 and from Ile du Levant $\left(43.02^{\circ} \mathrm{N}, 6.46^{\circ} \mathrm{E}\right)$ in France during SOP2. Both LOAC aerosol and ECC ozone sensors were integrated with Meteo Modem Company global positioning system (GPS) M10 radiosondes (RSs). Temperature, horizontal wind speed, and wind direction are sampled every $1 \mathrm{~s}(\approx 5-\mathrm{m}$ heights $)$ and have a resolution of $0.1 \mathrm{~K}, 0.15 \mathrm{~ms}^{-1}$, and $0.1^{\circ}$ respectively. The capacitor-type humidity sensor of M10 GPS sondes produces humidity measurements with resolution and total instrumental error of 1 and $\pm 5 \%$ respectively. Global positioning system radio occultation (GPS-RO) measurements are obtained from CDAAC (COSMIC Data Analysis and Archive Center). About 120 vertical temperature profiles at altitudes from 2 to $40 \mathrm{~km}$ at longitudes of $20^{\circ} \mathrm{W}-$ $10^{\circ} \mathrm{E}$ and latitudes of $30-55^{\circ} \mathrm{N}$ are available between 26 and 29 July 2013.
Measurements have a high accuracy for temperatures $<1 \mathrm{~K}$ at heights between 5 and $25 \mathrm{~km}$ and vertical resolution varying from about $0.5 \mathrm{~km}$ in the lower stratosphere (LS) to $1.4 \mathrm{~km}$ at $40 \mathrm{~km}$ heights in the middle atmosphere (Kursinski et al., 1997; Kuleshov et al., 2016). Because GW fluctuations in both wet and dry temperature profiles might be biased by the effect of water vapour at heights below $10 \mathrm{~km}$, the study focuses on heights above $10 \mathrm{~km}$. For a lower limit of $1.4 \mathrm{~km}$ vertical wavelength $\left(\lambda_{\mathrm{V}}\right)$ in the upper troposphere and the lower stratosphere (UTLS), the corresponding horizontal line-of-sight resolution, i.e. the lower limit of horizontal wavelength $\left(\lambda_{h}\right)$ of an observed GW, is about $270 \mathrm{~km}$ (Kursinski et al. 1997; Hindley et al., 2015). If the horizontal line-of-sight and the horizontal wave vector are not aligned, GWs with shorter horizontal wavelength can be captured. Depending on the influence of the geometric wave parameters and the measurement geometry on a homogeneous spectrum of GWs in the range 100-1000 km horizontal and $1-10 \mathrm{~km}$ vertical wavelengths, more than $80 \%$ of GW total variance of the spectrum can be derived (Lange and Jacobi, 2003). Previous climatological studies of GWs in the stratosphere have been derived from GPS-RO data (Tsuda et al., 2000; Liou et al., 2006). In particular, Chane Ming et al. (2014) used GPS-RO data to complement RS observations and model the characterisation of mesoscale GWs produced by a tropical meteorological event: the tropical cyclone Ivan over the south-west Indian Ocean.

\section{Methodology and analyses}

\subsection{Pre-processing and noise reduction}

Vertical profiles of temperature, horizontal wind speed, and ozone concentration are first re-sampled with a $5 \mathrm{~m}$ vertical resolution applying a cubic spline interpolation. Profiles of LOAC aerosol concentration are interpolated at every $50 \mathrm{~m}$ using a nearest neighbour interpolation. Then, vertical profiles are filtered using a discrete wavelet transform (DWT) also called multiresolution analysis. Multiresolution is well adapted for the analysis and the decomposition of multiscale wave-like structures in geophysical signals $(\mathrm{Ku}-$ mar and Foufoula-Georgiou, 1997; Domingues et al., 2005). Conventional filters often alter amplitudes and/or phase of the original signal when filtering out high-frequency structures. Implementing finite impulse response filters with properties, such as perfect flatness in the passband, very fast decay at the frequency cut-off, and linear phase response, is difficult and expensive. In this study, the wavelet decomposition consists of the fast application of an orthogonal filter bank; i.e. a set of iterations such that the remaining signal (the approximation) becomes coarser and coarser after each iteration. Then the signal can be perfectly reconstructed by adding all details and the approximation of the signal at the $n$th order of the iteration (refer to Eq. 1 in Chane Ming et 
al., 2000a). The smoothness or the number of vanishing moments of the wavelet are important in theoretical and practical studies (Pollicott and Weiss, 2008) because it ensures fast decay and limits the wavelet to capture high-order polynomial behaviour in a noisy signal. But more wavelet values are needed to capture most of the energy of the signal when the smoothness of the wavelet increases; i.e. the support of the wavelet is less compact (Walker, 2008). Compact support orthogonal bases with high orders of smoothness, such as the eighth-order Daubechies wavelet, ensures energy conservation and a very good localisation both in space and frequency for the analysis of GWs in the lower and middle atmosphere. Applications of the pyramid algorithm and the eighth-order Daubechies wavelet coefficients are described in Chane Ming et al. (1999, 2000a). In this way, fine structures with $\lambda_{\mathrm{v}}<0.32 \mathrm{~km}$ are efficiently removed from resampled profiles.

Perturbation profiles are then extracted from filtered data using a numerical Butterworth infinite impulse response high-pass filter with a specific vertical wavelength cut-off between 5 and $7 \mathrm{~km}$ for temperature, horizontal wind, and ozone concentrations. Background temperature and horizontal wind profiles result from the difference between the original and perturbation profiles. A high-order Butterworth filter is commonly used to simulate an ideal filter with maximally flat and linear phase responses in the passband. A fourth-order Butterworth filter provides a good compromise between the cost of implementation and the frequency decay $\left(-80 \mathrm{~dB} \mathrm{decade}^{-1}\right)$. Because of the high variability of aerosol concentration with altitude, the DWT is used to extract perturbations of aerosol concentration with a vertical wavelength cut-off of $6.4 \mathrm{~km}$.

Figure 1 shows examples of $50 \mathrm{~m}$ interpolated continuous vertical distributions of aerosol concentrations with diameters of $0.2-50 \mu \mathrm{m}$ in the troposphere and the stratosphere up to an altitude of $35 \mathrm{~km}$. Different shapes of vertical distribution are observed. In particular, Fig. 1c visualises a stratospheric aerosol layer with high values of aerosol concentration in which thin layers of strong local enhancements are embedded. Severe storms with numerous lightning strikes occurred in France for cases in Fig. 1a, c, and d. The examination of the whole aerosol data set indicates a day-today variability of aerosols in the UTLS. Other cases reveal that aerosol content was low in the UTLS during the 2013 ChArMEx.

\subsection{Detection of GW structures}

Cases, for which aerosol layers are visualised in the UTLS, are analysed by the continuous wavelet transform (CWT) to detect GW signatures (Chane Ming et al., 2000a). The continuous wavelet transform with Morlet complex-valued mother wavelet is applied to perturbation profiles of temperature, horizontal wind speed, ozone and concentration of aerosols to produce altitude-wavelength representations of the modulus of CWT coefficients, also called scalograms. For vertical profiles in Fig. 1, scalograms capture similar signatures of wave-like structures with vertical wavelengths between 1 and $4 \mathrm{~km}$ in dynamical parameters and tracer constituents of ozone and aerosols in the UTLS, which are explained by the presence of GWs. The case on 27 June 2013 is described in Sect. 4.

The European Center for Medium-Range Weather Forecasts (ECMWF) model is an operational numerical weather prediction model, which can explicitly resolve stratospheric GWs with horizontal and vertical wavelengths $>200 \mathrm{~km}$ and $>2 \mathrm{~km}$ respectively (Shutts and Vosper, 2011; Chane Ming et al., 2014; Preusse et al., 2014). Distributions of vertical velocity and horizontal wind divergence produce snapshots of GW structures. A one-dimensional (1-D) fast Fourier transform (FFT) in latitude is applied on 6-hourly ECMWF operational analyses with $1.125^{\circ} \times 1.125^{\circ}$ resolution at $50 \mathrm{hPa}$ (about $21 \mathrm{~km}$ ) in the LS to produce spectral densities of dominant GWs as a function of latitudes and horizontal wavelengths.

\subsection{Characterisation of GWs}

Conventional methods detailed in Chane Ming et al. (2010), such as the hodograph analysis, the SPARC Gravity Wave Initiative Radiosonde Data, and Stokes' parameter methods (Eckermann, 1996; Vincent et al., 1997), are applied to RS vertical perturbation profiles to provide characteristics of GWs (energy densities, momentum fluxes, and spectral parameters). The hodograph analysis computes the intrinsic frequency from the elliptical axis ratio, which is determined from variances of horizontal wind perturbations as a function of altitude. Combined conventional methods (CCM) based on the SPARC and Stokes' parameter methods ensure good estimation of GW spectral characteristics. The wavenumber, the direction of horizontal propagation, and the phase speed of horizontal propagation are derived from the SPARC method and the intrinsic frequency is obtained from the Stokes' parameter method.

At a given altitude, the horizontal wavelength can be deduced from adjacent vertical profiles of temperature close in time and space in order to observe the same GW packet. If the time variation in the phase difference is neglected (refer to Eq. 5 in Wang and Alexander, 2010), the phase shift divided by the distance provides the horizontal wavenumber projected along the line connecting the two profiles. Ern et al. (2004) introduced this method to estimate a horizontal wavelength of GWs and global absolute values of vertical flux of horizontal momentum at $25 \mathrm{~km}$ altitude from adjacent temperature profiles from Cryogenic Infrared Spectrometers and Telescopes for the Atmosphere (CRISTA). The method is adapted to pairs and triads of RO temperature profiles using the S-transform and CWT in the altitude range of 17.5-22.5 km with temporal windows of 4 and $2 \mathrm{~h}$ (Wang and Alexander, 2010; Faber et al., 2013). To better 


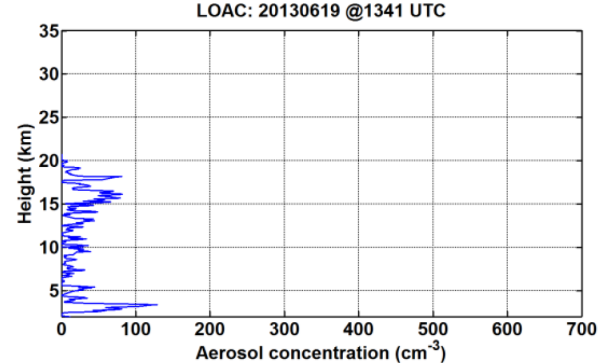

(a)

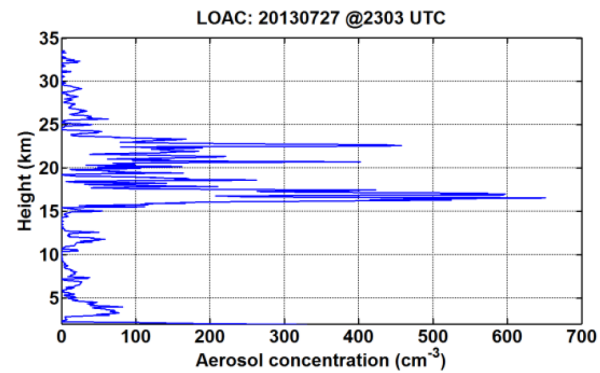

(c)

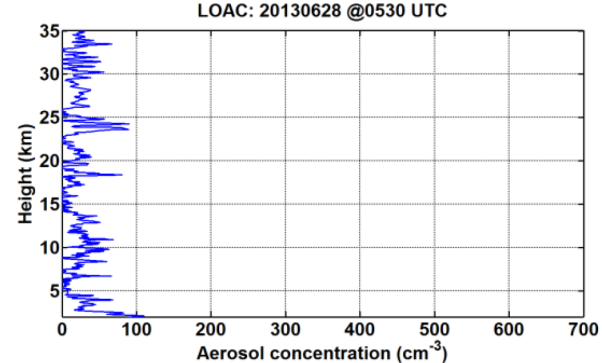

(b)

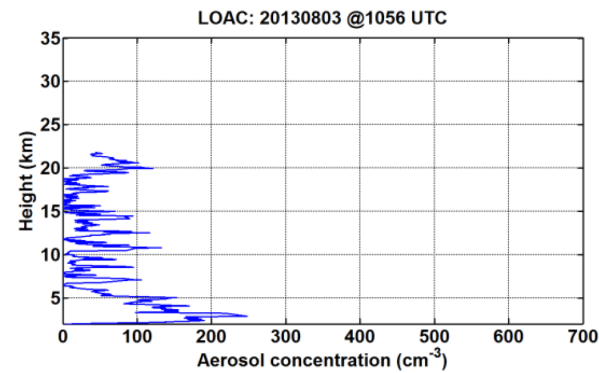

(d)

Figure 1. $50 \mathrm{~m}$ interpolated vertical profiles of aerosol concentration $\left(\mathrm{cm}^{-3}\right)$ with diameters $0.2-50 \mu \mathrm{m}$ above Minorca Island $\left(39.99^{\circ} \mathrm{N}\right.$, $\left.4.25^{\circ} \mathrm{E}\right)(\mathbf{a}-\mathbf{b})$ on 19 June at 13:41 UTC and 28 June at 05:30 UTC respectively, and above Ile du Levant $\left(43.02^{\circ} \mathrm{N}, 6.46^{\circ} \mathrm{E}\right)(\mathbf{c}-\mathbf{d})$ on 27 July at 23:03 UTC and 3 August at 10:56 UTC during the 2013 ChArMEx campaign.

constrain estimated horizontal wavelengths and momentum fluxes, Schmidt et al. (2016) used temporal and spatial windows of $15 \mathrm{~min}$ and $250 \mathrm{~km}$

\subsection{Simulated GWs}

The GW parameters are used to initialise a model based on the simplified linear wave polarisation relations for vertically propagating internal waves in a rotating fluid (Gill, 1982; Chane Ming et al., 2002) to produce synthetic vertical profiles of temperature and horizontal winds with GW signatures. Input parameters are vertical wavelength, intrinsic frequency, direction of horizontal propagation, localisation, altitude range, amplitude of temperature perturbation, and mean profiles of temperature and horizontal winds. The horizontal wavelength is derived from the GW-dispersion relationship. A Gaussian-shaped sinusoidal pulse is first computed at the observed altitude range from temperature perturbations. Based on the simplified linear wave polarisation relations, vertical wind perturbations are derived from temperature perturbations. Then the horizontal wind perturbations result from the vertical wind perturbations when the rotated frame of reference is aligned along the horizontal wavenumber. The direction of horizontal wave propagation is finally used to rotate the frame of reference to obtain observed horizontal wind perturbations. The synthetic profiles result from the sum of perturbations and observed background profiles.

\subsection{Ray tracing}

The gravity wave regional or global ray tracer (GROGRAT) is a 4-D ray-tracing model of the propagation and amplitude evolution of non-hydrostatic GWs in a rotating, stratified, compressible slowly varying background described by numerically gridded fields of temperature, wind, and pressure or geopotential height in the lower and middle atmosphere. It is based on the dispersion and refraction of the ray paths and includes parameterisations of turbulent and radiative wave damping and of wave-amplitude saturation. A full description of the model can be found in Marks and Eckermann (1995) and Eckermann and Marks (1997).

The validity of the Wentzel-Kramers-Brillouin (WKB) condition based on the slow variation of the vertical wavenumber with height ensures an approximate solution of the GW ray-tracing equations. Previous studies have shown that GROGRAT is an efficient tool to identify GW sources (Guest et al., 2000, 2002; Pramitha et al., 2015) and to simulate GW-background interactions such as GW effects, wave filtering, space and time variability of GW activity and characteristics (Wei and Zhang, 2015). For example, GROGRAT simulations help to interpret global GW observed morphology derived from satellite observations (Preusse et al., 2009). In this study, the model GROGRAT is run with observed GW spectral characteristics in a regional background of 6hourly operational ECMWF analyses of temperature, horizontal wind, and geopotential height with resolutions of 
25 pressure levels $(1000-1 \mathrm{hPa})$ and $1.125^{\circ} \times 1.125^{\circ}$ in the horizontal plane.

\subsection{Parcel advection method}

The parcel advection method is based on an analytical formula for the linear response of minor constituents to nondissipating hydrostatic internal GW motions when photochemical response of the constituent can be negligible, especially for long-lived tracers. The method was used for GWinduced perturbations in ozone, water vapour, and other constituents such as nitrogen dioxide and sodium (Randel et al., 1990; Teitelbaum et al., 1994). When the photochemical response of the constituent is negligible, in the linear simplified case, normalised ozone mixing ratio perturbations as a function of altitude are linked to normalised potential temperature perturbations by a coefficient $R(z)$, which is the ratio of vertical gradients of ozone and of the potential temperature background. Chane Ming et al. (2000b) illustrated the method to produce a climatology of laminae with vertical wavelengths $<5 \mathrm{~km}$ induced by GWs and horizontal advection in the UTLS near the southern subtropical barrier. The method also revealed the presence of GWs on vertical ozone profiles collected at Macquarie Island $\left(54^{\circ} \mathrm{S}, 159^{\circ} \mathrm{E}\right)$ during the Airborne Southern Hemisphere Ozone Experiment/Measurements for Assessing the Effects of Stratospheric Aircraft (ASHOE/MAESA) observation programme in 1994 (Chane Ming et al., 2003). Eckermann et al. (1998) formalised the method to derive analytical formulas for the response of vertical constituent profiles of arbitrary shape to adiabatic GWs. In particular, they showed that the parcel method becomes inaccurate for non-hydrostatic GWs and if the wave-induced photochemical response produces a significant diabatic feedback on the GW for shorter-lived constituents.

\section{Synoptic situation on 27 July 2013}

A heat wave accompanied by severe thunderstorms affected the whole of France during July 2013, especially during the second part of the month from 15 to 28 July with local maximum temperatures $>35^{\circ} \mathrm{C}$ on $25-27$ July. Météo-France ranked it the third hottest July since 1900. As for thunderstorm activity, a total of 527496 lightning strikes were registered. The most severe stormy episode of the year occurred on 27 July 2013 when both synoptic observations and forecasts indicated the presence of a meteorological pattern similar to an upper level jet streak. A jet streak is characterised by localised wind maxima along the axis of a jet stream and often referred to as a jet-front system because it is generally found in association with frontal zones in the UT (Cunningham and Keyser, 2003). Right entrance and left exit regions of jet streaks (with right and left set by the axis of the jet core and defined facing downstream) are preferred areas of storm development characterised by front systems (Lin, 2007). Climatologies at latitudes of North America reveal that jet streaks are intrinsically linked to tornado and severe storm reports (Rose et al., 2004; Clark et al., 2009). From a climatological survey of such synoptic patterns, Uccellini and Koch (1987) showed the existence of mesoscale GW disturbances, which can have a large influence on the weather conditions. For operational forecasting and detection of such GWs, Koch and O'Handley (1997) proposed a conceptual model with location of GW occurrence in a diffluent region bounded by the $300 \mathrm{hPa}$ ridge axis to the north-east and the $300 \mathrm{hPa}$ inflection axis to the south-west. The southern boundary of the wave region is defined by the location of a surface warm front. Numerical mesoscale studies also support exit regions of jet-front systems at the cold side of surface front as a favourable area of GW generation (O'Sullivan and Dunkerton, 1995; Zhang, 2004). Recently Plougonven and Zhang (2014) presented a review of current knowledge and understanding of GWs near jets and fronts from observations, theory, and modelling including jet streaks.

On 27 July 2013, mean wind speed was about $150 \mathrm{~km} \mathrm{~h}^{-1}$ near the tropopause above the western part of France. A sequence of 15 min georeferenced infrared GMS-3 satellite images reveals increasing convective activity associated with the jet-front system on 27 July from 03:00 UTC. Very warm, moist, and unstable air coming from the south triggered a strong mesoscale storm with a bow structure along the northwest coast of France propagating north-eastward in the afternoon of 27 July.

Figure 2a depicts the meteorological situation on 27 July at 12:00 UTC derived from operational ECMWF analyses, which represents a typical jet streak. Ucellini and Koch (1987) and Koch and O'Handley (1997) produced similar charts to depict the synoptic environment of jet streak typical occurrences of mesoscale GWs at the exit region of the upper-level jet streak. Isohypses on a $500 \mathrm{hPa}$ meteorological chart visualise the synoptic pattern with a strong minimum of geopotential heights located at $45^{\circ} \mathrm{N}$ latitude and $15^{\circ} \mathrm{W}$ longitude, which strengthens the jet wind field. Maximum wind speeds at $300 \mathrm{hPa}$ visualise the jet core over the west of Portugal. In addition wind speeds $>50 \mathrm{~ms}^{-1}$ from 12:00 UTC indicate presence of a significant jet streak. The height-longitude cross-section of potential vorticity at $43^{\circ} \mathrm{N}$ (not shown) demonstrates the presence of a tropopause fold $\left(6^{\circ} \mathrm{W}\right)$ located west of the jet $\left(4^{\circ} \mathrm{W}\right)$. This observation is supported by the cross-section of ozone mass mixing ratio visualizing a stratospheric intrusion of ozone in the middle troposphere at longitudes between 6 and $2^{\circ} \mathrm{W}$. Turbulent mixing processes within the tropopause fold are of first-order importance as a mechanism for stratospheric-tropospheric exchange (Shapiro, 1980). The jet streak dissipated on the afternoon of 28 July.

Backward air mass trajectories are calculated with the FLEXible TRAjectories (FLEXTRA) 5.0 code, a kinetic trajectory calculation code (Stohl et al., 1995, 2005). Trajec- 


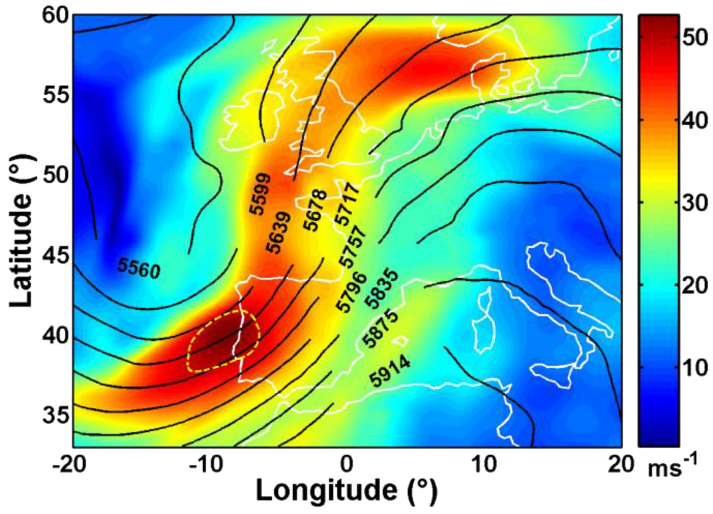

(a)

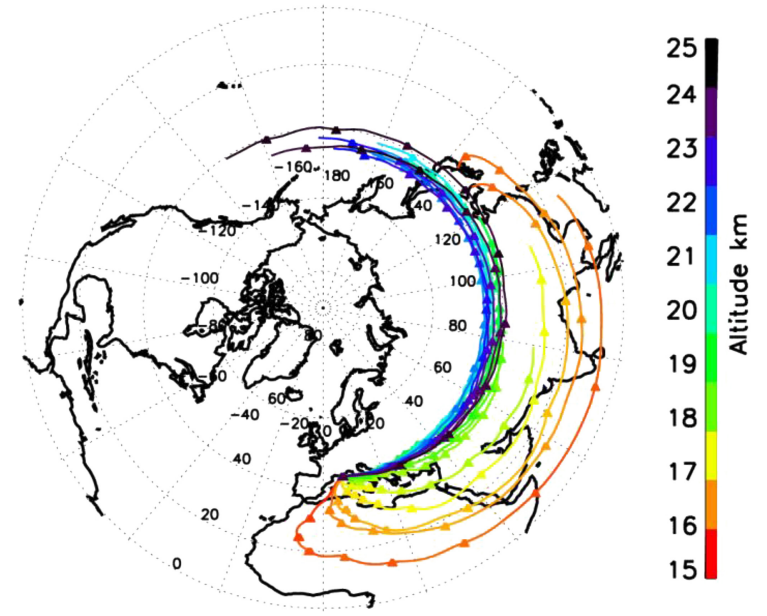

(b)

Figure 2. (a) Latitude-longitude distribution of wind speed $\left(\mathrm{ms}^{-1}\right)$ at $300 \mathrm{hPa}$ on 27 July at 12:00 UTC (colour scale: red relatively high values, blue relatively low values). Wind speed exceeds $>50 \mathrm{~ms}^{-1}$ above west of Portugal (yellow dashed line), solid lines indicate geopotential height (m) at $500 \mathrm{hPa}$ derived from ECMWF operational analyses on 27 July at 12:00 UTC, (b) Backward air mass trajectories using the FLEXTRA model starting at every $1 \mathrm{~km}$ height from levels of $15-25 \mathrm{~km}$ above Ile du Levant during 10 days from 27 July at 23:00 UTC, interval between two triangles corresponds to a duration of $24 \mathrm{~h}$. Colour indicates altitude $(\mathrm{km})$.

tories were initialised with global 3-hourly ECMWF wind fields with $1^{\circ} \times 1^{\circ}$ horizontal resolution during 10 days from 27 July at 23:00 UTC at every $1 \mathrm{~km}$ height between $15 \mathrm{~km}$ to $25 \mathrm{~km}$ above Ile du Levant (Fig. 2b). Trajectories reveal two different eastern air masses in the LS originated from tropical UT and mid-latitude LS. The vertical profile of aerosol concentration at Ile du Levant shows evidence of two layers of a large amount of aerosols with diameters between 0.2 and $0.7 \mu \mathrm{m}$ at altitudes of $15-20$ and $20-25 \mathrm{~km}$ and a mini- mum at $20 \mathrm{~km}$ where the zonal wind reverses (Fig. 3b). During a volcanically quiescent period, previous studies mention the presence of a stratospheric sulfate aerosol layer also called the Junge layer with a quasi-steady state relative maximum in particle number concentration $(r>0.1 \mu \mathrm{m})$ around $20 \mathrm{~km}$ in the mid-latitudes (Junge et al., 1961). Recent observations also reveal the presence of carbonaceous material in stratospheric aerosol (Murphy et al., 2007). In this study, the "speciation index" retrieved from the 12 and $60^{\circ}$ channel LOAC measurements suggests that the nature of stratospheric aerosols with diameters $<1 \mu \mathrm{m}$ is mainly carbonaceous in the LS on 27 July above Ile du Levant (Renard et al., 2016). Low aerosol content is observed in the LOAC profile of aerosol concentration on 28 July at 15:24 UTC when the jet streak dissipates after 12:00 UTC. Thus, dynamical processes might be involved in elaborating the local stratospheric aerosol background.

\section{Results}

The methodology and the analyses described in Sect. 3 are now applied to a case study on 27 July 2013.

\subsection{Detection of GWs}

Figure 3 visualises filtered resampled vertical profiles of temperature, potential temperature, horizontal winds, and ozone from radiosondes and the vertical profile of LOAC aerosol concentrations with diameters of $0.2-0.7 \mu \mathrm{m}$ on 27 July at 23:03 UTC above Ile du Levant.

In our study, GW analyses are applied on the sum over the size classes between 0.2 and $0.7 \mu \mathrm{m}$ of continuous vertical profiles of aerosol concentrations to derive a mean continuous vertical profile of aerosol concentrations. Because of the synoptic meteorological event, a sheared tropospheric jet is observed at $10 \mathrm{~km}$ height with maximum wind velocities $<20 \mathrm{~ms}^{-1}$ at altitudes of 6 and $14 \mathrm{~km}$, whereas larger amplitudes $\left(\approx 40 \mathrm{~ms}^{-1}\right)$ are observed at longitudes $<2.5^{\circ} \mathrm{W}$ at heights of about $12.5 \mathrm{~km}$. Perturbation profiles are obtained from subtraction between original and background profiles (Chane Ming et al., 2010). They show evidence of wave-like structures with short vertical wavelengths of $2-3 \mathrm{~km}$ in temperature and horizontal wind at heights of $13-20 \mathrm{~km}$. Maximum temperature and wind perturbations are about $3{ }^{\circ} \mathrm{C}$ and $5-7.6 \mathrm{~ms}^{-1}$ respectively, near the tropopause located at a height of $15 \mathrm{~km}$. Large variations in ozone and aerosol perturbations are also observed at altitudes of $15-20 \mathrm{~km}$. Thus the CWT is applied on vertical profiles of perturbations to localise wave-like structures in altitude-wavelength representations at heights below $23 \mathrm{~km}$ (refer to Sect. 3.2). The scalograms of the dynamical variables (temperature, wind) reveal a spectral signature with $2.6 \mathrm{~km}$ vertical wavelength at heights $10-20 \mathrm{~km}$ (Fig. 4a, b, c). For ozone and aerosols, similar peaks are found above $15 \mathrm{~km}$ (Fig. $4 \mathrm{~d}$, e). Such a 

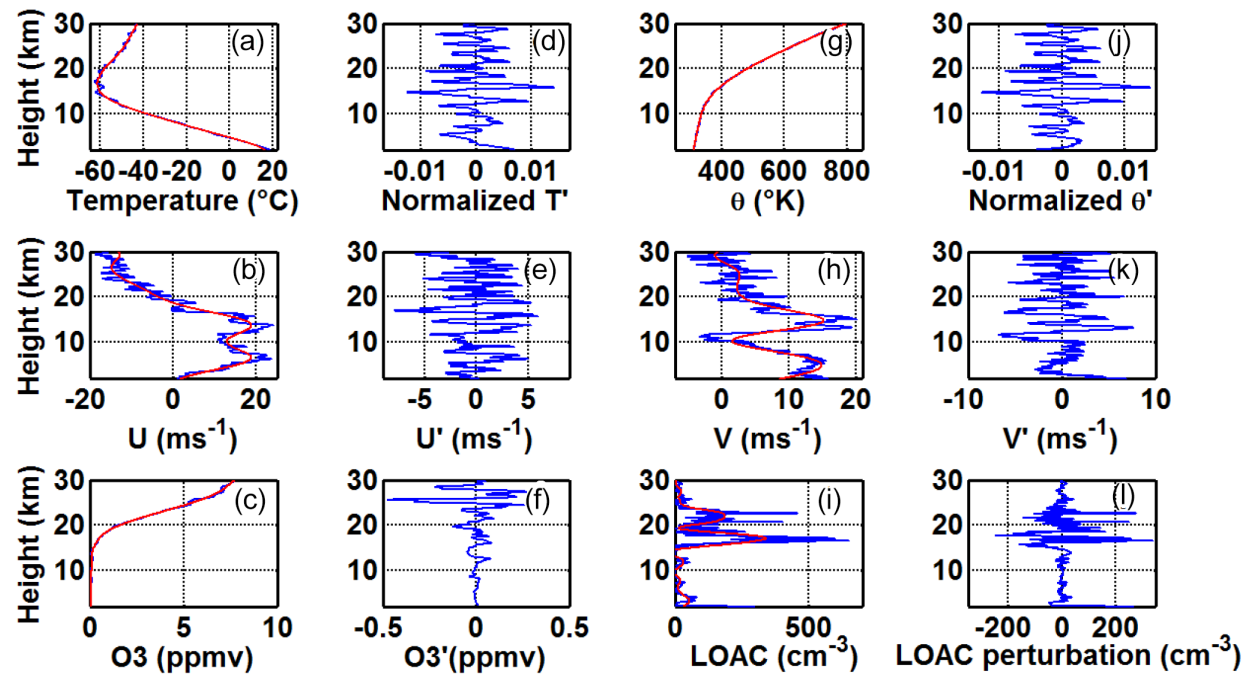

Figure 3. Filtered vertical profiles of temperature $\left({ }^{\circ} \mathrm{C}\right)$, potential temperature $\left({ }^{\circ} \mathrm{K}\right)$, zonal and meridional winds $\left(\mathrm{ms}^{-1}\right)$, ozone, LOAC aerosol concentration $\left(\mathrm{cm}^{-3}\right)$ of 0.2-0.7 $\mu$ m size classes $(\mathbf{a}, \mathbf{b}, \mathbf{c}, \mathbf{g}, \mathbf{h}, \mathbf{i})$ and perturbations $(\mathbf{d}, \mathbf{e}, \mathbf{f}, \mathbf{j}, \mathbf{k}, \mathbf{l})$ on 27 July at 23:03 UTC above Ile du Levant $\left(43.02^{\circ} \mathrm{N}, 6.46^{\circ} \mathrm{E}\right)$. Solid blue (red) line visualises filtered (background) profile. The prime symbol (') means perturbations.

pattern is also observed on CWTs of each vertical aerosol concentration profile of the five smallest size classes. Analyzing normalised ozone perturbation profiles would enhance the ozone peak at $13 \mathrm{~km}$ because of low level tropospheric ozone background whereas the use of ozone perturbation profiles focuses on wave-like structures observed at $15-23 \mathrm{~km}$ heights. The cross-sections of potential vorticity and ozone mixing ratio at $43^{\circ} \mathrm{N}$ indicate that the peak at $13 \mathrm{~km}$ heights results from a local stratospheric intrusion at longitudes of $7-12^{\circ} \mathrm{W}$. The longitude-latitude maps at 250 $300 \mathrm{hPa}$ support the presence of a filament structure of potential vorticity and ozone mass mixing ratio during the jetstreak event (not shown). These observations also suggest that aerosols observed on the LOAC profile at the same altitude are of stratospheric origin on 27 July at 12:00 UTC (Plumb et al., 1994).

The Morlet CWT local maxima also called "skeleton" (Chane Ming et al., 2000a) provide a continuous distribution of dominant wave-like structures with the vertical wavelength of $2-3 \mathrm{~km}$ at heights between 3 and $25 \mathrm{~km}$ with maxima at heights of $13-18 \mathrm{~km}$ in zonal wind perturbations (not shown). The mean vertical wavelength is estimated at about $2.5 \mathrm{~km}$ at altitudes of $3-7 \mathrm{~km}$. The amplitudes as well as the mean vertical wavelength decrease rapidly at altitudes above $19 \mathrm{~km}$ likely because waves are filtered near the critical level where intensity of zonal wind approaches zero. The FFT also supports the presence of wave-like structures with vertical wavelengths of $2-3.5 \mathrm{~km}$ at heights of $13-23 \mathrm{~km}$ in all analysed parameters (Fig. 4f). The DWT decomposition reveals that RS horizontal wind perturbations $\left(u^{\prime}\right.$ and $\left.v^{\prime}\right)$ with dominant vertical wavelengths of $2-3 \mathrm{~km}$ are in quadrature at heights of $14-26 \mathrm{~km}$ in agreement with the linear GWpolarisation relationship. The hodograph of wind perturba- tions visualises elliptical structures with characteristics of GWs with vertical wavelength of about $2 \mathrm{~km}$ at heights of $14-24 \mathrm{~km}$. The sign change at heights of $9-12 \mathrm{~km}$ with anticyclonic (cyclonic) rotation of the ellipse above $12 \mathrm{~km}$ (below $9 \mathrm{~km}$ ) indicates an upward (downward) flux of GW energy. This suggests that GW sources are localised at heights between 9 and $12 \mathrm{~km}$.

The analyses of vertical velocities in pressure coordinates $(\omega=\mathrm{d} p / \mathrm{d} t)$ derived from ECMWF operational analyses indicate that the numerical weather prediction model captures some wave-like structures on 27 July 2013 at 18:00 UTC in the LS (Fig. 5a). Figure 5a depicts mesoscale structures located over the eastern part of France. Spectral density of vertical velocities is calculated for longitudes of $10^{\circ} \mathrm{W}-20^{\circ} \mathrm{E}$ at latitudes between 42 and $48^{\circ} \mathrm{N}$. In particular, the energy of mesoscale wave-like structures with horizontal wavelengths in the east-west direction $\left(\lambda_{x}<500 \mathrm{~km}\right)$ is well localised at the latitude of $46^{\circ} \mathrm{N}$, which corresponds to the latitude of the exit region of the jet streak. Figure $5 \mathrm{~b}$ displays the energy distribution of dominant wave-like structures at latitudes of $42-48^{\circ} \mathrm{N}$ for horizontal wavelengths $\lambda_{x}<1200 \mathrm{~km}$. In particular, it highlights a continuous spectrum of GWs with horizontal wavelengths $\lambda_{x}$ of $400-800 \mathrm{~km}$ with a dominant mode of $400 \mathrm{~km}$ at latitudes of about $46^{\circ} \mathrm{N}$. The spectral densities at latitudes of $42-48$ and $46^{\circ} \mathrm{N}$ confirm that the mode of $400 \mathrm{~km}$ is dominant at $46^{\circ} \mathrm{N}$ within the wavelength range of $400-800 \mathrm{~km}$ (Fig. 5c). The vertical velocity data also reveal that the structure with amplitudes $<0.2 \mathrm{Pas}^{-1}$ extends at longitudes (latitudes) between $4^{\circ} \mathrm{W}$ to $10^{\circ} \mathrm{E}\left(42\right.$ to $\left.52^{\circ} \mathrm{N}\right)$.

The waves from this event can be identified in GPS-RO soundings as well. Figure 6a shows an overview of the GPSRO soundings over western Europe for 26 to 29 July 2013. We selected profiles for longitudes of $2.5-6^{\circ} \mathrm{E}$ and latitudes 

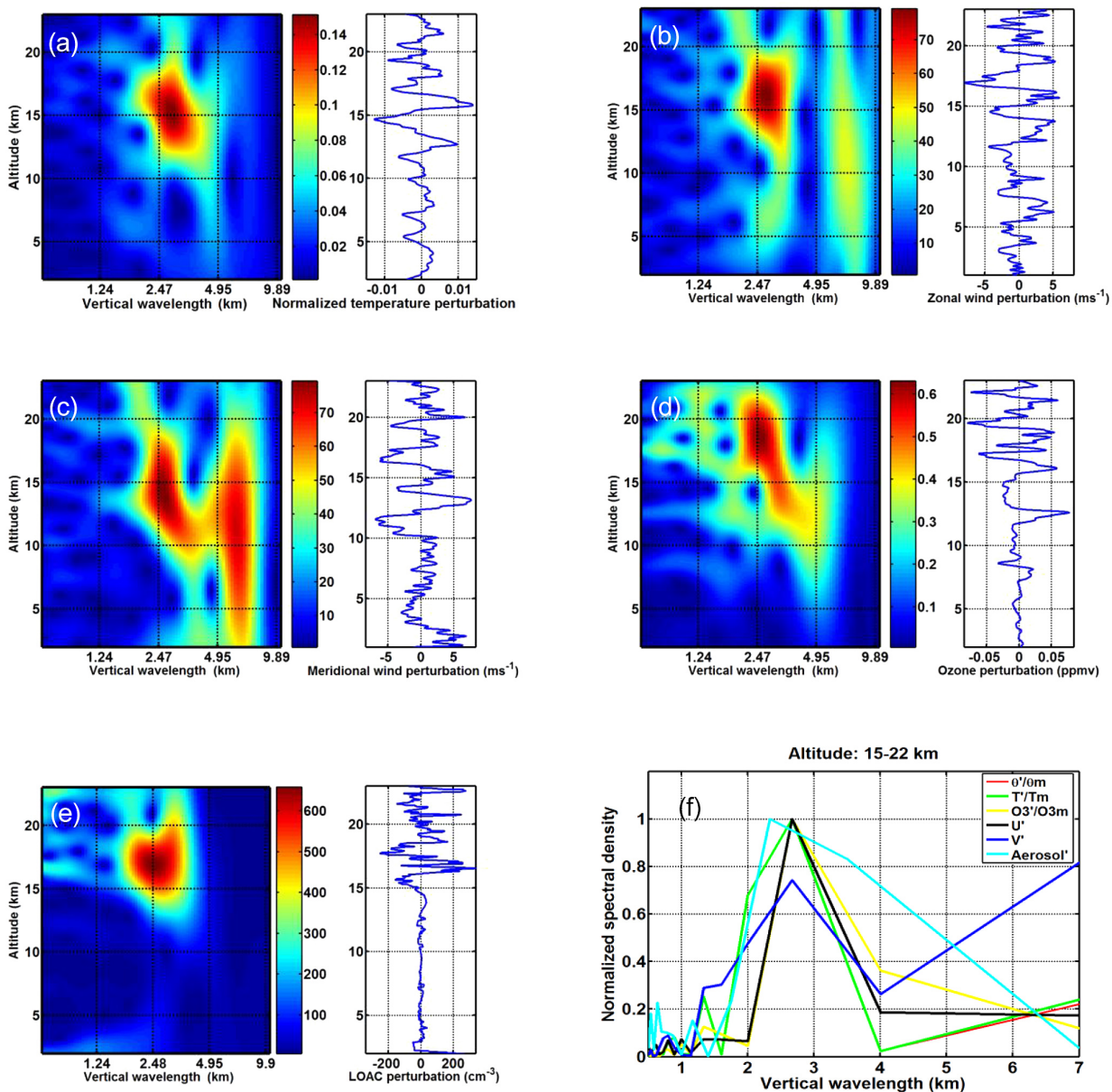

Figure 4. Morlet CWT of perturbations expressed as physical unit ${ }^{2} \mathrm{~km}^{-1}$ (left panels): (a) normalised potential temperature, (b, c) horizontal wind components $u$ and $v\left(\mathrm{~ms}^{-1}\right)$, respectively, and (d) ozone concentration in units of parts per million by volume (ppmv) and (e) aerosol concentration $\left(\mathrm{cm}^{-3}\right)$ of $0.2-0.7 \mu \mathrm{m}$ size classes. Perturbations are visualised on the right panels. Colour scale: red relatively high values, blue relatively low values. (f) Normalised fast Fourier transform of normalised potential temperature, normalised temperature, horizontal wind $\left(\mathrm{ms}^{-1}\right)$ and ozone (ppmv) and aerosol concentration $\left(\mathrm{cm}^{-3}\right)$ perturbations at heights of $15-22 \mathrm{~km}$.

of $40-50^{\circ} \mathrm{N}$ for spectral analysis of the altitude range of 10 $20 \mathrm{~km}$. The results are shown in Fig. 6b. The individual spectra are labelled by the day and UTC of the measurement (e.g. 2605 for 26 July; 05:00 UTC) and also marked accordingly in Fig. 6a. As one can see from results for consecutive days, GWs are enhanced starting from 27 July, peak at 28 July and are still active on 29 July. Spectral density peaks are found for wavelengths $2-3.5 \mathrm{~km}$, especially from 27 July at 06:00 UTC to 29 July in the morning with a maximum observed on 28 July early in the morning.

\subsection{Spectral characteristics of GWs}

The hodograph analysis and the CCM (refer to Sect. 3.3) are applied on RS temperature and wind perturbations on 27 July at 23:03 UTC above Ile du Levant to compute spectral characteristics such as vertical and horizontal wavelengths, intrinsic frequencies, periods, directions of horizontal wave propa- gation, and wave energy densities (Table 1). Consistent spectral parameters are obtained by the two methods. In particular, the hodograph analysis reveals the presence of mesoscale inertia GWs with vertical and horizontal wavelengths of 2.6 and $440-510 \mathrm{~km}$ respectively, a period of about $12 \mathrm{~h}$, propagating southward at heights of $13-20 \mathrm{~km}$. Eastward dominant modes with similar vertical wavelength, a period of about $15 \mathrm{~h}$ and longer horizontal wavelengths $(\approx 1300 \mathrm{~km})$ are observed at heights of $20-26 \mathrm{~km}$. The horizontal phase speed of the mesoscale GW is estimated at about $6.8 \mathrm{~ms}^{-1}$ $\left(7.9 \mathrm{~ms}^{-1}\right)$ at heights of $13-20 \mathrm{~km}(20-26 \mathrm{~km})$. GWs with $1300 \mathrm{~km}$ horizontal wavelength have larger phase speed of about $24 \mathrm{~ms}^{-1}$ at heights of $20-26 \mathrm{~km}$. Consistent large values of total energy densities of about $16 \mathrm{Jkg}^{-1}$ and vertical flux of horizontal momentum of $0.05 \mathrm{~m}^{2} \mathrm{~s}^{-2}$ (vertical flux of zonal momentum $\overline{u^{\prime} w^{\prime}} \approx 0.045 \mathrm{~m}^{2} \mathrm{~s}^{-2}$ ) defined in Vincent et al. (1997) are calculated at heights of 13-20 km. Our computed value of vertical flux of horizontal momentum (about 
Table 1. Characteristics of dominant GWs on 27 July at 23:03 UTC above Ile du Levant using a hodograph analysis and combined conventional methods (bold font) on observed and simulated (marked by *) profiles. Values are derived from peaks of wave parameter distributions. Height: altitude range, $E_{\mathrm{t}}$ : total energy density, $E_{\mathrm{k}}$ : kinetic energy, $E_{\mathrm{p}}$ : potential energy, Phi: direction of horizontal wave propagation (clockwise from north), $\lambda_{\mathrm{V}}, \lambda_{\mathrm{h}}$ : vertical and horizontal wavelengths, $\omega / f$ : intrinsic frequency/inertial frequency, $T$ : period. Parentheses denote standard deviation. Units are in brackets.

\begin{tabular}{|c|c|c|c|c|c|c|c|c|}
\hline $\begin{array}{r}\text { Heights } \\
{[\mathrm{km}]}\end{array}$ & $\begin{array}{r}E_{\mathrm{t}} \\
{\left[\mathrm{J} \mathrm{kg}^{-1}\right]}\end{array}$ & $\begin{array}{r}E_{\mathrm{k}} \\
{\left[\mathrm{J} \mathrm{kg}^{-1}\right]}\end{array}$ & $\begin{array}{r}E_{\mathrm{p}} \\
{\left[\mathrm{J} \mathrm{kg}^{-1}\right]}\end{array}$ & $\begin{array}{r}\lambda_{\mathrm{V}} \\
{[\mathrm{km}]}\end{array}$ & $\begin{array}{r}\lambda_{\mathrm{h}} \\
{[\mathrm{km}]}\end{array}$ & $\omega / f$ & $\begin{array}{c}T \\
{[\mathrm{~h}]}\end{array}$ & $\begin{array}{l}\text { Phi } \\
{\left[{ }^{\circ}\right]}\end{array}$ \\
\hline $3-7$ & 11.3 & 7.6 & 3.7 & 2.6 & $\begin{array}{l}161(20) \\
204(10) \\
451(23)\end{array}$ & $\begin{array}{l}1.8(0.1) \\
1.6(0.1) \\
1.2(0.1)\end{array}$ & $\begin{array}{r}9.6(0.2) \\
11.1(0.5) \\
14.6(0.9)\end{array}$ & $236(12)$ \\
\hline $13-20$ & 16.6 & 12.3 & 4.3 & 2.6 & 483.5 (108.7) & $1.5(0.1)$ & $11.5(1.16)$ & $220(29)$ \\
\hline $20-23$ & 5.4 & 4.6 & 0.8 & 2 & $\begin{array}{r}850(34) \\
1260(241)\end{array}$ & $1.1(0.1)$ & $16.4(0.6)$ & $95(16)$ \\
\hline $13-20 *$ & 15.2 & 10.5 & 4.68 & 2.6 & $486.5(69.8)$ & $1.5(0.1)$ & $11(0.86)$ & $204(2.5)$ \\
\hline 13-20 & 15.7 & 11.3 & 4.4 & 2.6 & 510 & 1.47 & 12 & 204 \\
\hline $20-26$ & 6.1 & 5.1 & 1 & 2 & $\begin{array}{r}440 \\
1300\end{array}$ & 1.12 & 15.6 & 112 \\
\hline 13-20* & 15.5 & 10.5 & 5.1 & 2.4 & 370 & 1.68 & 11 & 205 \\
\hline
\end{tabular}

$8 \mathrm{mPa}$ ) is well beyond values of $1 \mathrm{mPa}$ and $0.02 \mathrm{~m}^{2} \mathrm{~s}^{-2} \mathrm{ob}-$ served in the LS in summer midlatitudes respectively, by Ern and Preusse (2012) over Europe from High Resolution Dynamics Limb Sounder (HIRDLS) observations and Zhang et al. (2014) from radiosondes over North America. Thus the value of vertical flux of horizontal momentum supports our statement that the case on 27 July 2013 represents a stronger GW event.

The ratio between kinetic and potential energy of GWs provides a spectral index ( $p$ ) of about 2.6-2.9, which is larger than the values of $p \sim 5 / 3$ in the middle atmosphere (Vincent et al., 1997). Hertzog et al. (2002) found values of $p$ in the range 1.5-2.2 for high-frequency GWs from super-pressure balloon measurements in the stratosphere. However, they suggest that values greater than 5 could be caused by enhancements of the velocity spectrum near the inertial frequency. A large decrease of total energy densities above heights of $20 \mathrm{~km}$ indicates that most tropospheric GWs are not transmitted to higher stratospheric layers. The wave energy propagates upward from the troposphere with a fraction of upward energy $F_{\text {up }}>86 \%(95 \%)$ at heights of $13-20 \mathrm{~km}(20-26 \mathrm{~km})$. In addition the hodograph analysis reveals the presence of mesoscale structures propagating south-westward with vertical and horizontal wavelengths of 2.6 and $161-451 \mathrm{~km}$ respectively, with periods of 10 $15 \mathrm{~h}$ at heights of 3-7 km in the lower troposphere. The $F_{\text {up }}$ value of about $60 \%$ suggests that wave energy equally propagates upward and downward below the dominant GW tropospheric source. Finally, conventional methods provide good estimates of spectral GW parameters as can be seen from consistent values of the two methods and the standard devia- tion computed for the hodograph analysis in particular for the observed dominant mesocale wave-like structures at heights of $13-20 \mathrm{~km}$. Similar results at heights of $13-20 \mathrm{~km}$ are also obtained by the CWT method described in Chane Ming et al. $(2002,2003)$.

Figure $7 \mathrm{a}$ visualises temperature profiles from $\mathrm{RS}$ at 23:03 UTC (hereafter called RS2723) on 27 July above Ile du Levant and RO at 02:00 UTC (hereafter called RO2802) and 12:00 UTC (hereafter called RO2812) on 28 July. As observed on the RS2723 temperature profile, GPS RO temperature profiles also show evidence of small-scale perturbations in the troposphere and the LS. Scalograms of RO2802 and RO2812 temperature perturbations support the presence of dominant GW structures with vertical wavelengths of 2.5$3 \mathrm{~km}$ at heights of $10-18 \mathrm{~km}$ on 28 July (Fig. $7 \mathrm{~b}, \mathrm{c}$ ). By assuming that the same GW packet is observed on RS2723 and RO2802 profiles in the LS, the phase shift $(\Phi)$ between perturbation profiles is calculated at the altitude of $17 \mathrm{~km}$ taking into account of the time variation (refer to Sect. 3.3) using a GW period of $12 \mathrm{~h}$ at heights of $15-20 \mathrm{~km}$ and a time difference of $1.8 \mathrm{~h}$ at the altitude of $17 \mathrm{~km}$ between RS and RO measurements. Using a distance of $179.14 \mathrm{~km}$ between temperature profiles, the phase shifts $(\Phi)$ of 1.67 radians provide a horizontal wavelength of $673.6 \mathrm{~km}$. The estimated horizontal wavelength is larger than the "real" value by a factor of $1 / \cos \alpha$, where $\alpha$ is the angle between the connecting line of the two profiles and the real horizontal wave vector (Preusse et al., 2002). Thus, the "real" horizontal wavelength is ranged between 396 and $674 \mathrm{~km}\left(\mathrm{Phi}=200 \pm 29^{\circ}\right)$. The result is consistent with values of horizontal wavelengths derived from applying conventional methods on RS2723 pro- 


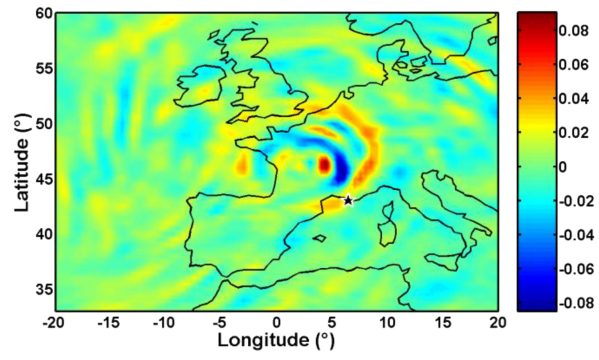

(a)

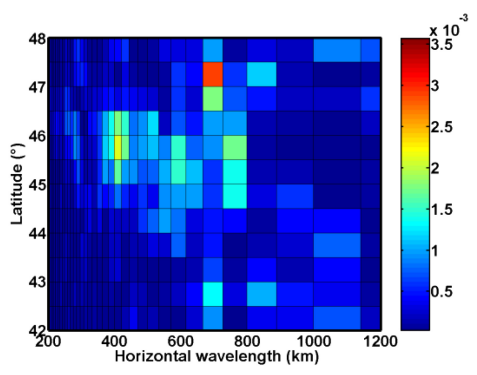

(b)

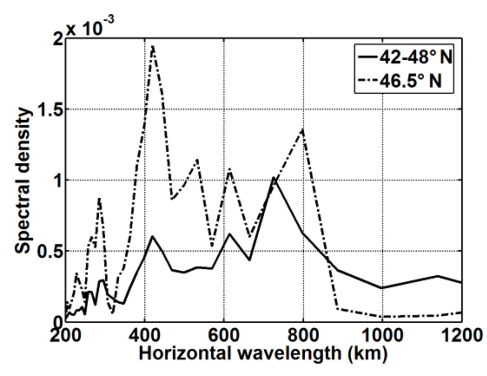

(c)

Figure 5. (a) Vertical velocity $\left(\mathrm{Pas}^{-1}\right)$ at $50 \mathrm{hPa}$ in the lower stratosphere derived from ECMWF analyses on 27 July 2013 at 18:00 UTC. The star symbol locates Ile du Levant. Colour scale: blue relatively negative high values, red relatively positive high values. (b) spectral density distribution $\left(\mathrm{Pa}^{2} \mathrm{~s}^{-2} \mathrm{~km}^{-1}\right)$ at latitudes ranged between 42 and $48^{\circ} \mathrm{N}$. Colour scale: red relatively high values, blue relatively low values. (c) spectral density at the latitudes of $42-48$ and $46^{\circ} \mathrm{N}$.

files at heights of 13-20 km. Using Eq. (7) reported in Ern et al. (2004), the vertical flux of momentum is estimated at $0.017-0.03 \mathrm{~m}^{2} \mathrm{~s}^{-2}$ at heights of $10-20 \mathrm{~km}$. The estimate is somewhat lower but compatible with the value of $0.05 \mathrm{~m}^{2} \mathrm{~s}^{-2}$ derived from the RS measurements. The characteristics of these GWs are consistent with previous observations of inertia GWs associated with a jet stream exit region (Thomas et al., 1999; Ravetta et al., 1999; Bertin et al., 2001).

Thus, both observations and ECMWF analyses suggest that the strong activity of GWs with vertical and horizontal wavelengths of $2-5 \mathrm{~km}$ and $<1200 \mathrm{~km}$ with dominant mesoscale structures of $400 \mathrm{~km}$ horizontal wavelength is as-

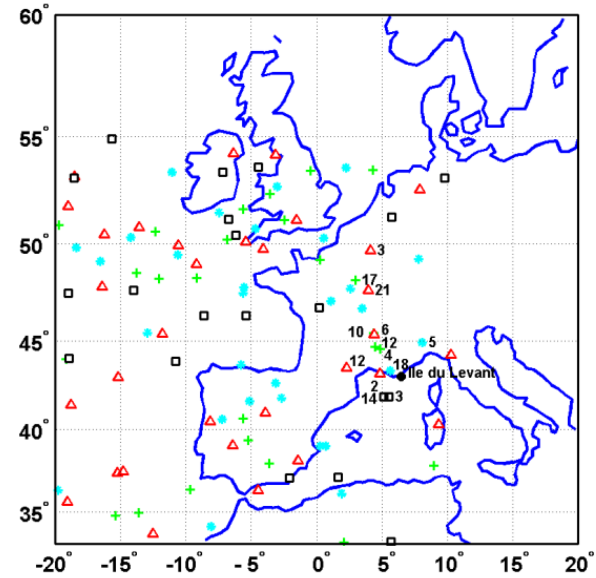

(a)

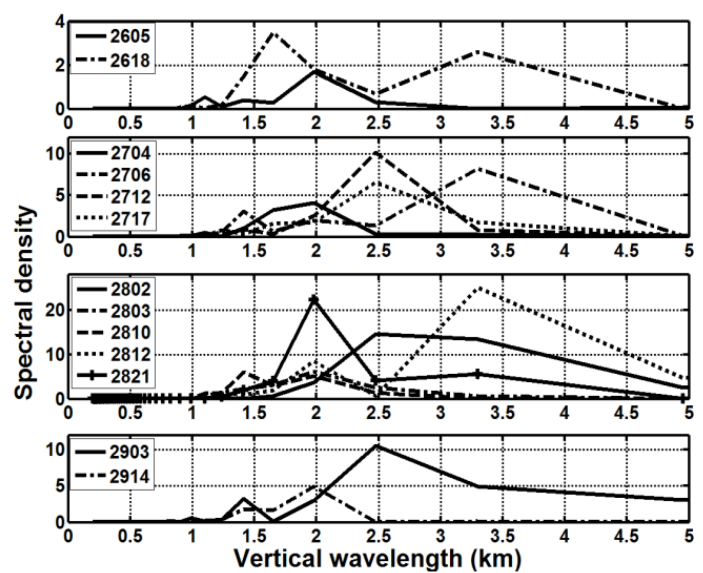

(b)

Figure 6. (a) Location of GPS-RO COSMIC data on 26, 27, 28, and 29 July 2013 marked with $*$, +, triangle, square symbols respectively. The black dot locates Ile du Levant. Numbers near markers indicate hours (UTC) of profiles from which (b) spectral densities $\left({ }^{\circ} \mathrm{C}^{2} \mathrm{~km}^{-1}\right)$ of GPS-RO temperature perturbations $\left({ }^{\circ} \mathrm{C}\right)$ are calculated for modes with vertical wavelengths $<5 \mathrm{~km}$ at altitudes of $10-20 \mathrm{~km}$ at heights of $10-20 \mathrm{~km}$ at longitudes of $2.5-6^{\circ} \mathrm{E}$ and latitudes of $40-50^{\circ} \mathrm{N}$ on $26,27,28$, and 29 July 2013 (upper panel to lower panel).

sociated with the jet-front system from 27 July afternoon to 28 July in the morning in the eastern part of France (refer to the following Sect. 5.1).

The observed characteristics at heights of $13-20 \mathrm{~km}$ are used in the next section to provide a simplified synthetic profiles of perturbations and to identify GW sources. 

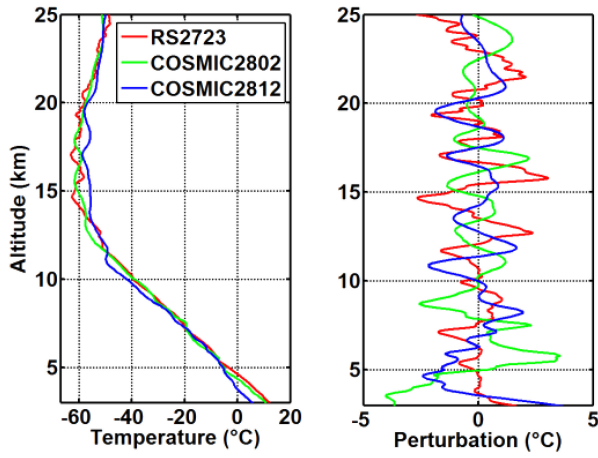

(a)
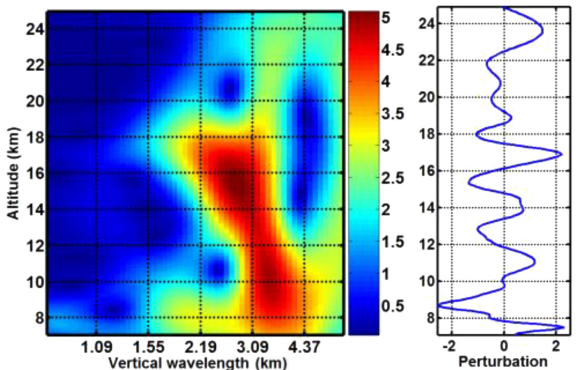

(b)

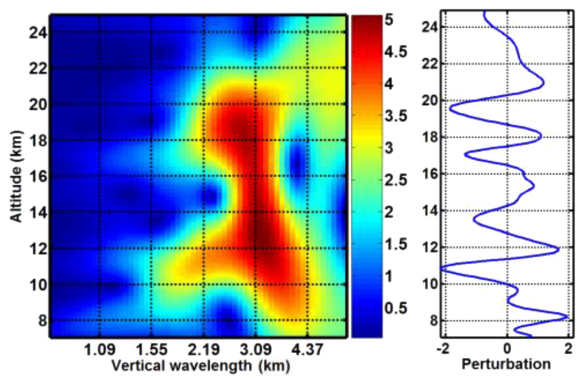

(c)

Figure 7. (a) Vertical profiles of temperature $\left({ }^{\circ} \mathrm{C}\right)$ and perturbations $\left({ }^{\circ} \mathrm{C}\right)$ on the left and right panels from RS and RO data on 27 July at 23:03, 28 July 2013 at 02:00 and 12:00 UTC respectively. Morlet CWT (left panel) of temperature perturbations (right panel) of GPS-RO data on 28 July 2013 at (b) 02:00 UTC and (c) 12:00 UTC. Colour scale: red relatively high values, blue relatively low values.

\subsection{Simulated profiles and ray tracing}

Mean values of spectral parameters observed at heights of $13-20 \mathrm{~km}$ (a vertical wavelength of $2.6 \mathrm{~km}$, a period of $11.7 \mathrm{~h}$, a direction of horizontal wave propagation clockwise from north of $204^{\circ}$ ) with upward propagation of energy at heights of $12.8 \mathrm{~km}$ with a height range of $14 \mathrm{~km}$ are
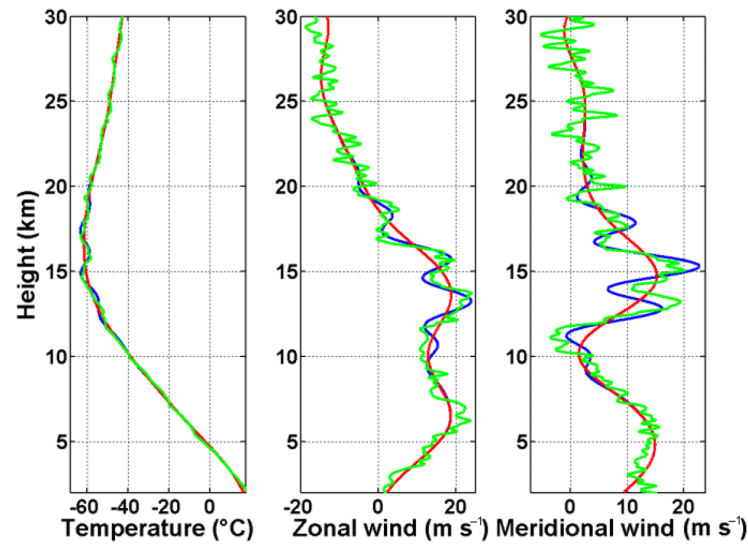

(a)

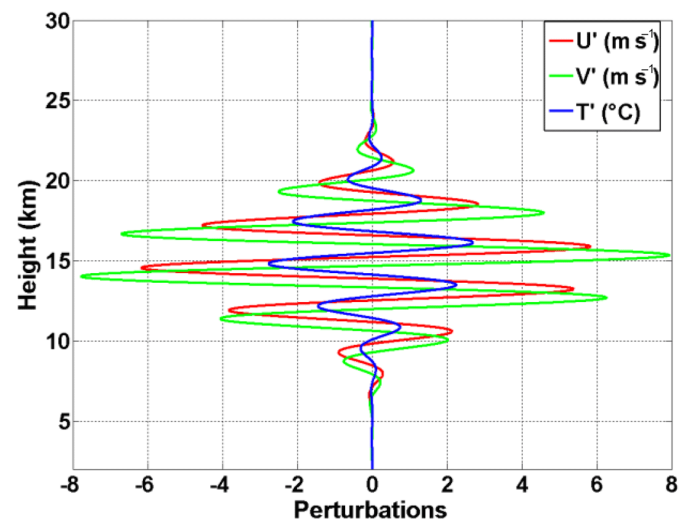

(b)

Figure 8. (a) Observed (green solid line) and simulated temperature (blue solid line) in units of ${ }^{\circ} \mathrm{C}$ (left panel) on 27 July at 23:03 UTC. The middle and right panels are similar to the left panel but for horizontal wind profiles $\left(\mathrm{ms}^{-1}\right)$. Red solid lines indicate the observed mean profile. (b) Simulated perturbation profiles using GW simplified linear wave polarisation relations. $U^{\prime}, V^{\prime}$, and $T^{\prime}$ are zonal wind $\left(\mathrm{ms}^{-1}\right)$, meridional wind $\left(\mathrm{ms}^{-1}\right)$, and temperature $\left({ }^{\circ} \mathrm{C}\right)$ perturbations respectively.

used to produce simplified synthetic RS profiles (refer to Sect. 3.4) with signatures of dominant mesoscale GWs with horizontal wavelengths of $499.9 \pm 45.7 \mathrm{~km}$. Filtered and simulated amplitudes, and phase relations of perturbations are in good agreement for the temperature and the horizontal wind (Fig. 8). The hodograph analysis and the CCM are applied on simulated profiles to retrieve spectral parameters (Table 1). The two methods provide good estimates of the input spectral parameters. These estimates are also in agreement with observed ones at heights of 13-20 km in terms of energy densities and the mean horizontal phase speed. The wave energy 
propagates upward from the troposphere with a fraction of upward energy $F_{\text {up }}>93 \%$ and a horizontal phase speed of $6.44 \mathrm{~ms}^{-1}$ at heights of $13-20 \mathrm{~km}$. In conclusion, the simplified synthetic RS profiles are consistent with observed RS profiles at heights of 13-20 km for the case study on 27 July 2013. Thus, mean characteristics of observed mesoscale inertia GW structures agree well with simplified linear GW theory and are the most energetic structures observed in the RS profiles on 27 July at heights of $13-20 \mathrm{~km}$. Thus, because of the shape of the mean wave-like structure observed at heights of $13-20 \mathrm{~km}$, the Morlet complex-valued mother wavelet reveals to be well adapted to analyse such a structure. The simplified synthetic RS profiles are used in the next section to interpret the impact of GWs on stratospheric tracers and aerosols.

The GROGRAT model (refer to Sect. 3.5) is used to identify sources of observed dominant mesoscale GWs at heights of $13-20 \mathrm{~km}$. Taking into account spreads of spectral parameters (refer to values of the two methods between parentheses in Table 1), spectral characteristics of the mesoscale inertia GW with horizontal wavelengths of 300-550 km (step of $20 \mathrm{~km}$ ), $\omega / f$ of $1.4-1.8$ (step of 0.1 ) and horizontal propagation direction of $200^{\circ}$ at heights of $19 \mathrm{~km}$ from 28 July at 00:00 UTC provide a discrete spectrum of 65 individual components to initialise the model. Backward ray trajectories are computed with the same parameterisations used in Guest et al. (2000). Almost all rays can be traced back to $12-17 \mathrm{~h}$ before release on 28 July at 00:00 UTC. Projected ray paths on the georeferenced infrared GMS-3 image at 12:00 UTC and the latitude-height cross section of zonal wind at longitude $0^{\circ}$ at 12:00 UTC reveal that ray paths terminate at the location of the cold frontal zone and at about heights of $10 \mathrm{~km}$ in the jet core on 27 July at 12:00 UTC at 2- $0^{\circ} \mathrm{W}$ longitudes and $42.5-45^{\circ} \mathrm{N}$ latitudes (Fig. 9a, b). Because rays pass over a convective region when the front system moves eastward, some GWs produced by convective sources might also be captured.

Figure 9c shows the evolution of the mean horizontal wavelength and the mean normalised intrinsic frequency as a function of altitude and mean time. The mean horizontal wavelength (mean period) decreases (increases) slowly from $440 \mathrm{~km}(10 \mathrm{~h})$ at $17 \mathrm{~km}$ heights to $290 \mathrm{~km}(14 \mathrm{~h})$ at $10 \mathrm{~km}$ heights. A given combination of wave parameters might preferentially be observed depending on the background wind field. A sensitivity test on the horizontal propagation direction varying between 170 and $230^{\circ}$ (with a step of $10^{\circ}$ ) produces similar results. The characteristics of GWs are consistent with numerical modelling studies of Zhang (2004) and Wang et al. (2009) on the generation of GWs in upper tropospheric jet-front systems. These studies reveal the production of mesoscale GWs lasting more than $24 \mathrm{~h}$ with very similar spectral characteristics $\left(\lambda_{h}=100-500 \mathrm{~km}, \lambda_{\mathrm{v}}=2 \mathrm{~km}\right.$, $\omega / f \approx 1.5$ ) in the troposphere and LS.

In conclusion, the GROGRAT simulation indicates that mesoscale GWs with a whole range of parameters around the mean parameter could be excited by the front and propagate to the location of Ile du Levant at heights of 13-20 km.

\subsection{GW induced perturbation in tracers and aerosol concentration}

To identify GW induced perturbation in tracers, the parcel advection method (refer to Sect. 3.6) is applied on profiles of ozone and potential temperature perturbations normalised by the background profiles on 27 July at 23:03 UTC (Fig. 10a). The normalised potential temperature perturbations are multiplied by smooth vertical profiles of coefficient $R(z)$ (Fig. 10b) and superimposed on normalised ozone perturbations. The amplitudes of perturbations exhibit comparable values at heights of 4-7 and 14-24 km for perturbations with vertical wavelengths $<5 \mathrm{~km}$. This supports the presence of GW signatures. The parcel advection method is not valid at heights of $7-14 \mathrm{~km}$ because the vertical gradient of the ozone background is very small, $R(z)$ strongly varies with altitude, and other tropospheric structures are present at 7.5 and $12.5 \mathrm{~km}$ (Chane Ming et al., 2000b). The parcel method also identifies GW signatures in temperature and ozone perturbation profiles on 28 July at 13:30 UTC (Fig. 10c and d). In comparison with Fig. 3, smaller values of normalised potential temperature perturbations are observed in the LS. It means that the intensity of stratospheric GWs is decreasing in the afternoon of 28 July. The Morlet CWTs of ozone and temperature perturbations depict similar monochromatic structures with vertical wavelength of about $1.5-3 \mathrm{~km}$ at heights of $10-15 \mathrm{~km}$. For these two cases, GW signatures can be observed in the lower troposphere above $3 \mathrm{~km}$. The parcel advection method is also valid for temperature and humidity mixing ratio. Figure $10 \mathrm{e}$ visualises wave-like structures on specific humidity profiles at heights above $3 \mathrm{~km}$. The spectral densities of perturbations (Fig. 10f) reveal wave-like structures of $1.5-3 \mathrm{~km}$ vertical wavelengths. The amplitudes of temperature and specific humidity perturbations are $\pi$ out of phase above $4 \mathrm{~km}$ height, which is in agreement with the parcel advection method with regards to signs of mean gradients. Thus, evidence of GW signatures in ozone and humidity in the lower troposphere supports that the dominant GW source is located in the jet core with an upward (downward) propagating energy above (below) the source. Thus, observations lead to the conclusion that mesoscale GWs observed on 27 July 2013 affected the variability of stratospheric ozonetracer fields.

Effects of GWs on stratospheric aerosols are investigated in perturbations of aerosol concentrations and dynamical parameters in the LS. The DWT is applied to aerosol concentrations to retrieve perturbations of aerosol concentrations with vertical wavelengths of $1.6-3.2 \mathrm{~km}$ and the mean profile with vertical wavelengths $>3.2 \mathrm{~km}$ (Fig. 11). Dominant wave-like structures with vertical wavelengths of 2$2.5 \mathrm{~km}$ are observed in the LS $(15-20 \mathrm{~km})$. The amplitudes of aerosol concentration perturbation strongly decrease at 


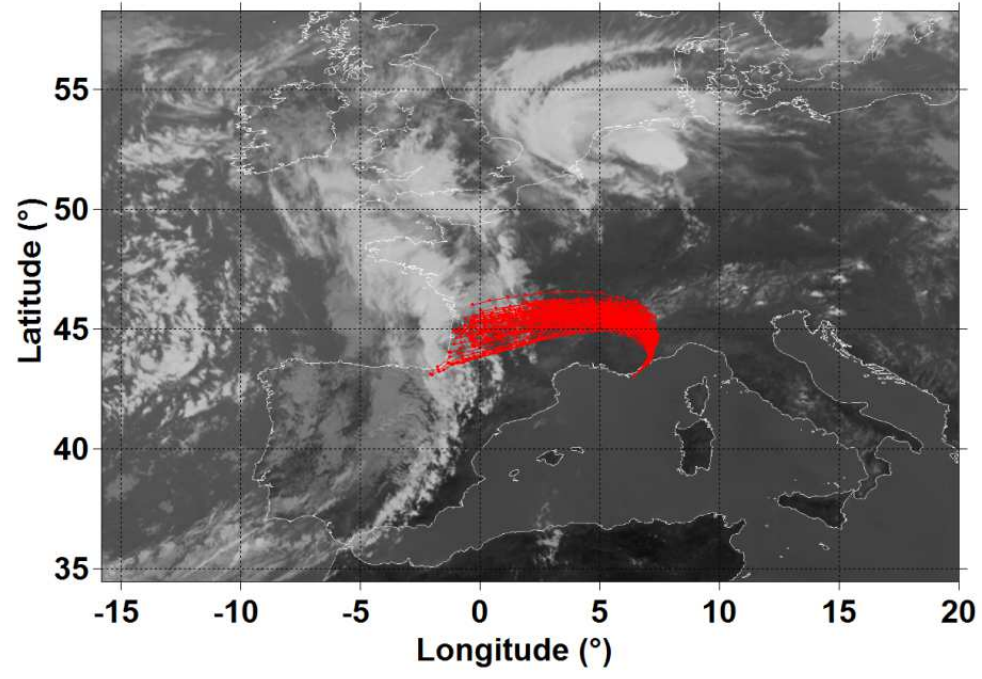

(a)

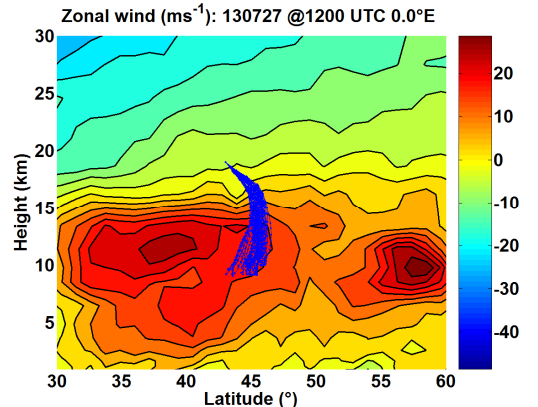

(b)

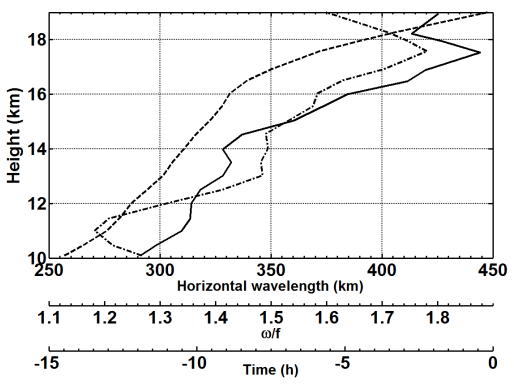

(c)

Figure 9. Backward rays from Ile du Levant launched at $19 \mathrm{~km}$ height on 28 July at 00:00 UTC onto (a) georeferenced infrared GMS-3 image and (b) altitude-latitude cross section (colour scale: red relatively high values, blue relatively low values) of zonal wind (ms ${ }^{-1}$ ) at longitude of $0.0^{\circ} \mathrm{E}$ on 27 July at 12:00 UTC. (c) Evolution of horizontal wavelength in units of kilometres (solid line), $\omega / f$ (dash-dot line) and time in units of hour (dashed line) as a function of altitude $(\mathrm{km})$.

heights of $20 \mathrm{~km}$ likely because of partial transmission of GWs through the wind field and the presence of two layers of stratospheric aerosols with different origins. The superimposition of synthetic vertical perturbation aerosol upon concentration perturbation profiles of the mean dominant mesoscale GW (Fig. 8b) indicates that perturbations of aerosol concentration and simulated vertical wind are in phase at heights of 15-19 km (Fig. 11b). The phase relationships do not agree with the parcel advection method for which perturbations should be in quadrature (refer to Eq. 24 in Eckermann et al., 1998). Aerosols behave differently from tracer gases with production and growth processes in the stratosphere. This case study suggests a possible correlation between vertical transport and the distribution of aerosol concentration in the LS. In addition, large amplitudes of stratospheric vertical wind with maximum values of $\pm 40 \mathrm{mms}^{-1}$ are induced by the mean mesoscale GW in comparison with monthly av- eraged amplitudes of stratospheric vertical wind of about $\pm 5 \mathrm{mms}^{-1}$ with an annual averaged of $\pm 1 \mathrm{mms}^{-1}$ (Gryazin and Beresnev, 2011). Recent theoretical studies reveal possible substantial effects of a background vertical motion on stratospheric aerosol distribution. Using a 4-D continuity equation for particles undergoing growth process, $\mathrm{Li}$ and Boer (2000) investigated the relative roles of condensation, particle fall velocity, vertical motion, and diffusion in determining the aerosol size distribution. Vertical motion could broaden the size distribution of the stratospheric background aerosol, which would tend to support a broader size distribution of the stratospheric background aerosol in the tropics. Gryazin and Beresnev (2011) suggested that the relative aerosol concentration is mostly controlled by the action of the vertical wind for particles with a size $<2.5 \mu \mathrm{m}$. Nilsson et al. (2000) proposed the use of the phase shift in perturbations of aerosol concentration and vertical wind to separate 


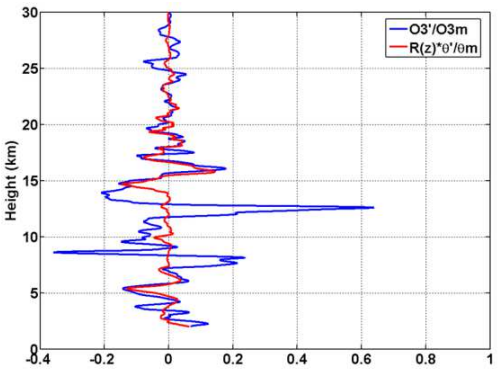

(a)

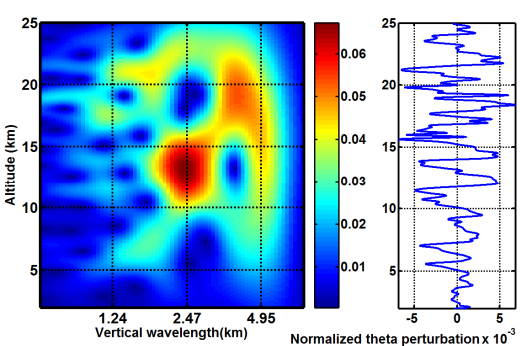

(c)
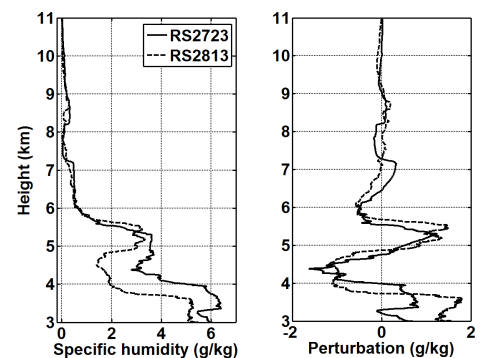

(e)

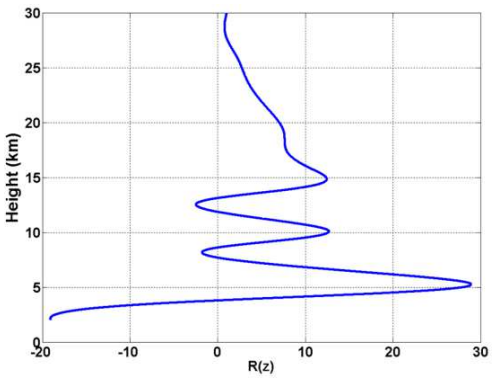

(b)

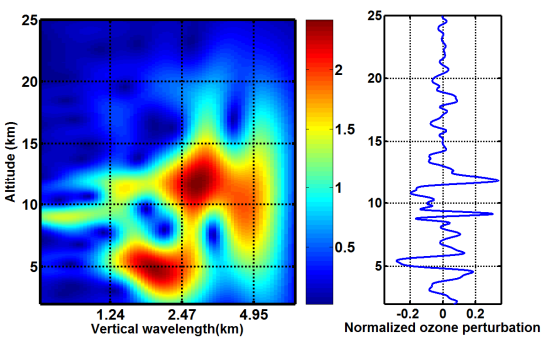

(d)

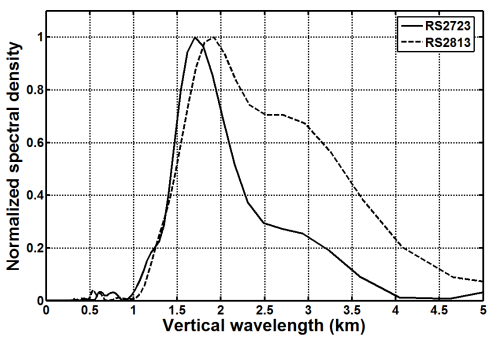

(f)

Figure 10. (a) Normalised perturbations of the temperature and the ozone mixing ratio for the vertical wavelength bandwidth of 1.2-4.8 km using DWT. Temperature perturbation $\left({ }^{\circ} \mathrm{C}\right)$ profile has been multiplied by the factor $R(z)$ (b) defined in Sect. 3.6. (c) and (d) Morlet CWT (left panels) of normalised temperature and ozone concentration (ppmv) perturbations (right panels) on 28 July at 13:30 UTC (colour scale: red relatively high values, blue relatively low values). (e) Specific humidity ( $\mathrm{g} \mathrm{kg}^{-1}$ ) and perturbations on 27 July at 23:03 UTC and 28 July at 13:30 UTC at heights of 3-11 km on left and right panels respectively, and (f) corresponding normalised spectral density of specific humidity.

the influence of turbulent fluxes of aerosols from the effect of nucleation responding on waves or turbulence. Perturbations should be $3 \pi / 4$ out of phase if nucleation dominates, whereas turbulence would cause perturbations to be in phase. With regard to GWs effects on cirrus clouds, the combination of a mountain wave and the jet-streak GW producing a wave-induced upward motion $>10 \mathrm{cms}^{-1}$ can cause ice supersaturation and trigger the formation of a cirrus cloud in the UT (Spichtinger et al., 2005). A strong link has been established between $\mathrm{GW}$-induced mesoscale variability in vertical velocities and climate forcing by cirrus (IPCC, 2007). Haag and Kärcher (2004) investigated the impact of aerosols and
GWs on cirrus clouds at northern mid-latitudes. They emphasise the importance to include small-scale temperature fluctuations caused by GWs for a good prediction of cloud physical properties in global models as well as to represent correctly changes in GW activity in a future climate. In the present study, strong modulation is also observed on amplitudes of stratospheric aerosol concentration background with size class of $0.2-0.7 \mu \mathrm{m}$ up to $60 \%$ of the background amplitude with the vertical spectral characteristic of the observed stratospheric mesoscale GW. 


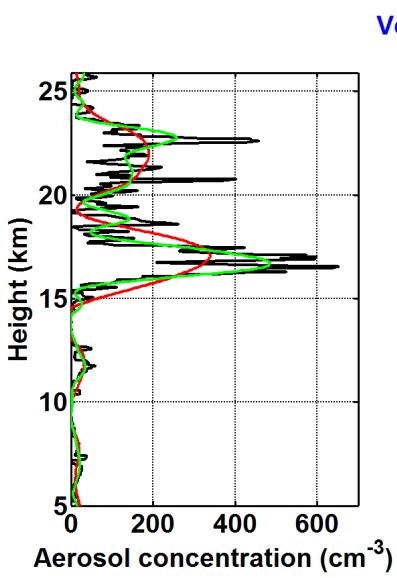

(a)

Vertical wind perturbation $\left(\mathrm{ms}^{-1}\right)$

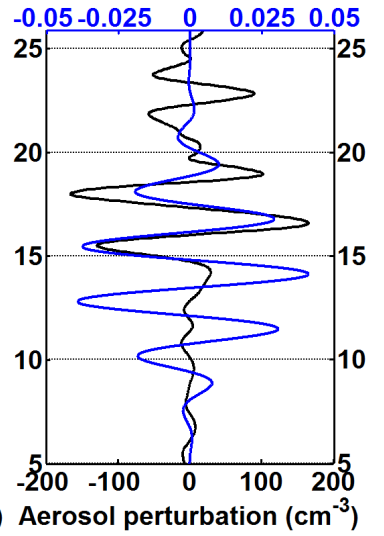

(b)

Figure 11. Vertical profiles of (a) aerosol concentration $\left(\mathrm{cm}^{-3}\right)$ and (b) aerosol (size class: $0.2-50 \mu \mathrm{m}$ ) perturbations with 1.6$3.2 \mathrm{~km}$ vertical wavelengths and simulated vertical wind perturbations $\left(\mathrm{ms}^{-1}\right)$ on 27 July at 23:03 UTC. On left panel, black (red) solid line corresponds to raw (background) profile $\left(\mathrm{cm}^{-3}\right)$. The sum of the background profile and GW-induced perturbations is drawn as a green solid line.

\section{Conclusions}

In this study, high-resolution observations of the new balloon-borne LOAC coupled with RS and ozonesonde observations are shown to capture short-scale wave-like structures in the UT and LS during the 2013 ChArMEx. A methodology and different complementary tools based on observations and modelling are proposed to describe GWs and to evaluate their effects on tracer constituents and the vertical distribution of aerosol concentration. The methodology is illustrated on a case study on 27 July 2013 when mesoscale inertia GWs were identified during a jet-streak event. Observations reveal a strong activity of dominant mesoscale inertia GWs with horizontal and vertical wavelengths of $370-510 \mathrm{~km}$ and $2-3 \mathrm{~km}$ respectively, and periods of $10-13 \mathrm{~h}$ propagating southward at altitudes of $13-20 \mathrm{~km}$ and eastward above $20 \mathrm{~km}$ during 27-28 July above Ile du Levant. Analyses from the European Centre for MediumRange Weather Forecasts also show evidence of mesoscale wave-like patterns with consistent wave properties above the eastern part of France. In addition, ray-tracing experiments highlight the jet-front system as the main source of observed GWs. Such GWs induce strong local short-scale perturbations in the amplitudes of tracer constituents, such as ozone and tropospheric water vapour as well as the stratospheric aerosol background layer. Simplified synthetic profiles of temperature and wind perturbations are derived from the linear wave polarisation relations with signatures of dominant mesoscale GWs with a mean horizontal wavelength of about $500 \mathrm{~km}$ at heights of $13-20 \mathrm{~km}$. The synthetic pro- file of stratospheric vertical velocity perturbations produces a wave-induced upward motion with a maximum amplitude of $40 \mathrm{mms}^{-1}$ more than 10 times larger than usual amplitudes of stratospheric vertical wind. In addition, the profile of wave-induced upward motion reveals to be in phase with perturbations of stratospheric aerosol concentrations (size class of $0.2-0.7 \mu \mathrm{m}$ ). Besides the role of temperature perturbations especially for nucleation at high frequencies, present results also support the importance of GW spectral characteristics and GW-induced vertical wind perturbations in the vertical aerosol distribution as also observed in formation of ice supersaturation below the tropopause where cirrus clouds are observed (Spichtinger et al., 2005). In addition, results from our study lead to the conclusion that mesoscale GWs might affect significantly the vertical background distribution of stratospheric aerosol concentrations.

A strategy of highly regular balloon launches has been set up using the LOAC instrument in particular to investigate the short-term variations of the vertical profile of the tropospheric and stratospheric aerosols using weather balloons in the framework of VOLTAIRE (VOLatils-Terre, Atmosphère et Interactions-Ressources et Environnement) since December 2013. Balloon-borne LOACs are launched regularly (twice per month) at northern mid-latitudes and occasionally at other latitudes. In our future research, this analysis will be extended to a substantial data set to investigate the occurrence of GW effects on LOAC vertical profiles of stratospheric aerosol concentrations. These preliminary results do not exclude a possible threshold on GW amplitudes to trigger the GW-aerosol relation. In the future, mesoscale modelling coupled with an analytical stratospheric aerosol model will enable us to better describe the wave source mechanisms and to quantify the efficiency of such adiabatic reversible transient events to shape the stratospheric aerosol background.

\section{Data availability}

The ChArMEx data set is available at http://mistrals.sedoo. fr/ChArMEx/. Global positioning system radio occultation (GPS-RO) measurements are obtained from CDAAC (COSMIC Data Analysis and Archive Center): http://cdaac-www. cosmic.ucar.edu.

Acknowledgements. The LOAC project was funded by the French National Research Agency's ANR ECOTECH. The LOAC and the gondola were built by the Environnement-SA and Meteo Modem companies. The balloon flights of the ChArMEx campaign were funded and performed by the French Space Agency CNES. The ozone and LOAC sondes used in the campaign were funded with the support of CNES, ADEME, and INSU-CNRS in the framework of the MISTRALS Programme. This scientific work was financially supported by the French Labex VOLTAIRE (Laboratoire d'Excellence ANR-10-LABX-100-01) and the French project, StraDyVariUS ANR-13-BS06-0011-01. The satellite images were provided by Météo-France/Centre de Météorologie Spatiale. 
Dr Stephen D. Eckermann provided the GROGRAT software. The model was run on the supercomputer of the University of La Réunion. The authors thank Brice Barret for leading the TOSCA-IASI project, which has supported the balloon soundings in Minorca and the staff from Laboratoire d'Aérologie (Toulouse) for associated operational activities. They also thank the editor and the anonymous reviewers for their helpful comments on our manuscript.

Edited by: W. Lahoz

\section{References}

Bacmeister, J. T., Eckermann, S. D., Tsias, A., Carslaw, K. S., and Peter, T.: Fluctuations induced by a spectrum of gravity waves: A comparison of parameterizations and their impact on stratospheric microphysics, J. Atmos. Sci., 56, 1913-1924, 1999.

Bertin, F., Campistron, B., Caccia, J. L., and Wilson, R.: Mixing processes in a tropopause fold observed by a network of ST radar and lidar, Ann. Geophys., 19, 953-963, 2001.

Carslaw, K. S., Peter, T., Bacmeister, J., and Eckermann, S. D.: Widespread solid particle formation by mountain waves in the Arctic stratosphere, J. Geophys. Res., 104, 1827-1836, 1999.

Chane Ming, F., Molinaro, F., and Leveau, J.: Wavelet techniques applied to lidar signal in the analysis of the middle atmosphere dynamics, Applied Signal Processing, 6, 95-106, 1999.

Chane Ming, F., Molinaro, F., Leveau, J., Keckhut, P., and Hauchecorne, A.: Analysis of gravity waves in the tropical middle atmosphere over La Reunion Island $\left(21^{\circ} \mathrm{S}, 55^{\circ} \mathrm{E}\right)$ with lidar using wavelet techniques, Ann. Geophys., 18, 485-498, doi:10.1007/s00585-000-0485-0, 2000a.

Chane Ming, F., Molinaro, F., Leveau, J., Keckhut, P., Hauchecorne, A., and Godin, S.: Vertical short-scale structures in the upper tropospheric-lower stratospheric temperature and ozone at La Reunion Island (20.8S, 55.3E), J. Geophys. Res., 105, 2685726866, 2000b.

Chane Ming, F., Roff, G., Robert, L., and Leveau, J.: Gravity waves characteristic over Tromelin Island during the passage of cyclone Hudah, Geophys. Res. Lett., 29, 18-1-18-4, doi:10.1029/2003JD003489, 2002.

Chane Ming, F., Guest, F. M., and Karoly, D. J.: Gravity waves observed in temperature, wind and ozone data over Macquarie island, Aust. Meteorol. Mag., 52, 11-21, 2003.

Chane Ming, F., Chen, Z., and Roux, F.: Analysis of gravity-waves produced by intense tropical cyclones, Ann. Geophys., 28, 531547, doi:10.5194/angeo-28-531-2010, 2010.

Chane Ming, F., Ibrahim, C., Barthe, C., Jolivet, S., Keckhut, P., Liou, Y.-A., and Kuleshov, Y.: Observation and a numerical study of gravity waves during tropical cyclone Ivan (2008), Atmos. Chem. Phys., 14, 641-658, doi:10.5194/acp-14-641-2014, 2014.

Clark, A. J., Schaffer, C. J., Gallus Jr., W. A., and JohnsonO'Mara, K.: Climatology of storm reports relative to upper-level jet streaks, Weather Forecast., 24, 1032-1051, 2009.

Cunningham, P. and Keyser, D.: Encyclopedia of Atmospheric Sciences, Academic Press, 1043-1055, 2003.
Deshler, T.: A review of global stratospheric aerosol: measurements, importance, life cycle, and local stratospheric aerosol, Atmos. Res., 90, 223-232, 2008.

Domingues, M. O., Mendes, O., and Mendes da Costa, A.: On wavelet techniques in atmospheric sciences, Adv. Space Res., 35 , 831-842, 2005.

Eckermann, S. D.: Hodographic analysis of gravity waves: relationships among Stokes parameters, rotary spectra and cross- spectral methods, J. Geophys. Res., 101, 19169-19174, 1996.

Eckermann, S. D. and Marks, C. J.: GROGRAT: A new model of the global propagation and dissipation of atmospheric gravity waves, Adv. Space Res., 20, 1253-1256, 1997.

Eckermann, S. D., Gibson-Wilde, D. E., and Bacmeister, J. T.: Gravity wave perturbations of minor constituents: A parcel advection methodology, J. Atmos. Sci., 55, 3521-3539, 1998.

Ern, M. and Preusse, P.: Gravity wave momentum flux spectra observed from satellite in the summer time subtropics: Implications for global modeling, Geophys. Res. Lett., 39, L15810, doi:10.1029/2012GL052659, 2012.

Ern, M., Preusse, P., Alexander, M. J., and Warner, C. D.: Absolute values of gravity wave momentum flux derived from satellite data, J. Geophys. Res., 109, D20103, doi:10.1029/2004JD004752, 2004.

Ern, M., Ploeger, F., Preusse, P., Gille, J. C., Gray, L. J., Kalisch, S., Mlynczak, M. G., Russell, J. M., and Riese, M.: Interaction of gravity waves with the QBO: A satellite perspective, J. Geophys. Res., 119, 2329-2355, doi:10.1002/2013JD020731, 2014.

Faber, A., Llamedo, P., Schmidt, T., de la Torre, A., and Wickert, J.: On the determination of gravity wave momentum flux from GPS radio occultation data, Atmos. Meas. Tech., 6, 3169-3180, doi:10.5194/amt-6-3169-2013, 2013.

Fan, J., Yuan, T., Comstock, J. M., Ghan, S., Khain, A., Leung, L. R., Li, Z., Martins, V. J., and Ovchinnikov, M.:Dominant role by vertical wind shear in regulating aerosol effects on deep convective clouds, J. Geophys. Res., 114, D22206, doi:10.1029/2009JD012352, 2009.

Fritts, D. C. and Alexander, M. J.: Gravity wave dynamics and effects in the middle atmosphere, Rev. Geophys., 41, 1003, doi:10.1029/2001RG000106, 2003.

Geller, M. A., Alexander, M. J., Love, P. T., Bacmeister, J., Ern, M., Hertzog, A., Manzini, E., Preusse, P., Sato, K., Scaife, A. A., and Zhou, T.: A comparison between gravity wave momentum fluxes in observations and climate models, J. Climate, 26, 6383-6405, 2013.

Gill, A. E.: Atmosphere-Ocean Dynamics, Academic Press, 131139, 1982.

Gryazin, V. and Beresnev, S. A.: Influence of vertical wind on stratospheric aerosol transport, Meteorol. Atmos. Phys., 110, 151-162, 2011.

Guest, F. M., Reeder, M. J., Marks, C. J., and Karoly, D. J.: Inertia gravity waves observed in the lower stratosphere over Macquarie Island, J. Atmos. Sci., 57, 737-752, 2000.

Guest, F. M., Reeder, M. J., and Chane Ming, F.: Analyses of inertiagravity waves in upper-air soundings made from Macquarie Island, Aust. Meteorol. Mag., 51, 107-15, 2002. 
Haag, W. and Bärcher, B.: The impact of aerosols and gravity waves on cirrus clouds at midlatitudes, J. Geophys.Res., 109, D12202, doi:10.1029/2004JD004579, 2004.

Hamill, P., Jensen, E. J., Russell, P. B., and Bauman, J. J.: The life cycle of stratospheric aerosol particles, B. Am. Meteorol. Soc., 7, 1395-1410, 1997.

Hertzog, A., Vial, F., Mechoso, C. R., Basdevant, C., and Cocquerez, P.: Quasi-lagrangian measurements in the lower stratosphere reveal an energy peak associated with near-inertial waves, Geophys. Res. Lett., 29, 1229, doi:10.1029/2001GL014083, 2002

Hindley, N. P., Wright, C. J., Smith, N. D., and Mitchell, N. J.: The southern stratospheric gravity wave hot spot: individual waves and their momentum fluxes measured by COSMIC GPS-RO, Atmos. Chem. Phys., 15, 7797-7818, doi:10.5194/acp-15-7797$2015,2015$.

Hobbs, P. V.: Aerosol-cloud-climate interations, Academic Press, 1993.

Hommel, R., Timmreck, C., Giorgetta, M. A., and Graf, H. F.: Quasi-biennial oscillation of the tropical stratospheric aerosol layer, Atmos. Chem. Phys., 15, 5557-5584, doi:10.5194/acp-155557-2015, 2015.

IPCC: Contribution of Working Group I to the Fourth Assessment Report of the Intergovernmental Panel on Climate Change, Cambridge University Press, Cambridge, United Kingdom and New York, NY, USA, 2007.

Junge, C. E., Changnon, C. W., and Manson, J. E.: Stratospheric aerosols, J. Meteorol., 18, 81-108, 1961.

Koch, S. and O'Handley, C.: Operational forecasting and detection of mesoscale gravity waves, Weather Forecast., 12, 253-281, 1997.

Komhyr, W.: Electrochemical concentration cells for gas analysis, Ann. Geophys., 25, 203-210, 1969.

Kuleshov, Y., Choy, S., Fu, E. F., Chane-Ming, F., M., Liou, Y.-A., and Pavelyev, A. G.: Analysis of meteorological variables in the Australasian region using ground- and spacebased GPS techniques, Atmos. Res., 176-177, 276-289, doi:10.1016/j.atmosres.2016.02.021, 2016.

Kumar, P. and Foufoula-Georgiou, E.: A new look at rainfall fluctuations and scaling properties of spatial rainfall using orthogonal wavelets, J. Appl. Meteorol., 32, 209-222, 1993.

Kursinski, E. R., Hajj, G. A., Schofield, J. T., Linfield, R. P., and Hardy, K. R.: Observing Earth's atmosphere with radio occultation measurements using the Global Positioning System, J. Geophys. Res., 102, 23429-23465, doi:10.1029/97JD01569, 1997.

Lange, M. and Jacobi, C.: Analysis of gravity waves from radio occultation measurements, Springer Berlin, 479-484, 2003.

Li, J. and Boer, G. J.: The continuity equation for the stratospheric aerosol and its characteristic curves, J. Atmos. Sci., 57, 442-451, 2000

Lin, Y. L.: Mesoscale dynamics, Cambridge University Press, 379437, 2007

Liou, Y. A., Pavelyev, A. G., Wicker, J., Liu, S. F., Pavelyev, A. A., Schmidt, T., and Igarashi, K.: Application of GPS radio occultation method for observation of the internal waves in the atmosphere, J. Geophys. Res., 111, D06104, doi:10.1029/2005JD005823, 2006.

Lurton, T., Renard, J.-B., Vignelles, D., Jeannot, M., Akiki, R., Mineau, J.-L., and Tonnelier, T.: Light scattering at small angles by atmospheric irregular particles: modelling and laboratory measurements, Atmos. Meas. Tech., 7, 931-939, doi:10.5194/amt-7-931-2014, 2014.

Marks, C. J. and Eckermann, S. D.: A three-dimensional nonhydrostatic ray-tracing model for gravity waves: Formulation and preliminary results for the middle atmosphere, J. Atmos. Sci., 52, 1959-1984, 1995.

Matsumura, T., Hayashi, M., Fujiwara, M., Matsunaga, K., Yasui, M., Saraspriya, S., Manik, T., and Suripto, A.: Observations of Stratospheric Aerosols by Balloon-borne Optical Particle Counter at Bandung, Indonesia, J. Meteorol. Soc. Jap., 79, 709718, 2001.

Murphy, D. M., Cziczo, D. J., Hudson, P. K., and Thomson, D. S.: Carbonaceous material in aerosol particles in the lower stratosphere and tropopause region, J. Geophys. Res., 112, D04203, doi:10.1029/2006JD007297, 2007.

Nilsson, E. D., Pirjola, L., and Kulmala, M.: The effect of atmospheric waves on aerosol nucleation and size distribution, J. Geophys. Res., 105, 19917-19926, 2000.

O'Sullivan, D. and Dunkerton, T. J.: Generation of inertia-gravity waves in a simulated life cycle of baroclinic instability, J. Atmos. Sci., 52, 3695-3716, 1995.

Plougonven, R. and Zhang, F.: Internal gravity waves from atmospheric jets and fronts, Rev. Geophys., 52, 33-76, doi:10.1002/2012RG000419, 2014

Plumb, R. A., Waugh, D. W., Atkinson, R. J., Newman, P. A., Lait, L. R., Schoeberl, M .R., Browell, E. V., Simmons, A. J., and Loewenstein, M.: Intrusions into the lower stratospheric Arctic vortex during the winter of 1991/92, J. Geophys. Res., 99, 10891105, 1994.

Pollicott, M. and Weiss, H.: How Smooth is Your Wavelet? Wavelet Regularity via Thermodynamic Formalism, Commun. Math. Phys., 281, 1-21, 2008.

Pramitha, M., Venkat Ratnam, M., Taori, A., Krishna Murthy, B. V., Pallamraju, D., and Vijaya Bhaskar Rao, S.: Evidence for tropospheric wind shear excitation of high-phase-speed gravity waves reaching the mesosphere using the ray-tracing technique, Atmos. Chem. Phys., 15, 2709-2721, doi:10.5194/acp-15-27092015, 2015.

Preusse, P., Dornbrack, A., Eckermann, S. D., Riese, M., Schaeler, B., Bacmeister, J. T., Broutman, D., and Grossmann, K. U.: Space-based measurements of stratospheric mountain waves by CRISTA, J. Geophys. Res., 107, 8178, doi:10.1029/2001JD000699, 2002.

Preusse, P., Eckermann, S. D., Ern, M., Oberheide, J., Picard, R. H., Roble, R. G., Riese, M., Russell, J. M., and Mlynczak, M. G.: Global ray tracing simulations of the SABER gravity wave climatology, J. Geophys. Res., 114, D08126, doi:10.1029/2008JD011214, 2009.

Preusse, P., Ern, M., Bechtold, P., Eckermann, S. D., Kalisch, S., Trinh, Q. T., and Riese, M.: Characteristics of gravity waves resolved by ECMWF, Atmos. Chem. Phys., 14, 10483-10508, doi:10.5194/acp-14-10483-2014, 2014.

Randel, W., Boville, B. A., and Gille, J. C.: Observations of planetary mixed Rossby-gravity waves in the upper stratosphere, J. Atmos. Sci., 47, 3092-3099, doi:10.1175/1520-0469, 1990.

Renard, J.-B., Dulac, F., Berthet, G., Lurton, T., Vignelles, D., Jégou, F., Tonnelier, T., Thaury, C., Jeannot, M., Couté, B., Akiki, R., Verdier, N., Mallet, M., Gensdarmes, F., Charpentier, 
P., Mesmin, S., Duverger, V., Dupont, J. C., Elias, T., Crenn, V., Sciare, J., Giacomoni, J., Gobbi, M., Hamonou, E., Olafsson, H., Dagsson-Waldhauserova, P., Camy-Peyret, C., Mazel, C., D'ecamps, T., Piringer, M., Surcin, J., and Daugeron, D.: LOAC: a small aerosol optical counter/sizer for ground-based and balloon measurements of the size distribution and nature of atmospheric particles - Part 2: First results from balloon and unmanned aerial vehicle flights, Atmos. Meas. Tech. Discuss., 8, 10057-10096, doi:10.5194/amtd-8-10057-2015, 2015.

Renard, J.-B., Dulac, F., Berthet, G., Lurton, T., Vignelles, D., Jégou, F., Tonnelier, T., Jeannot, M., Couté, B., Akiki, R., Verdier, N., Mallet, M., Gensdarmes, F., Charpentier, P., Mesmin, S., Duverger, V., Dupont, J.-C., Elias, T., Crenn, V., Sciare, J., Zieger, P., Salter, M., Roberts, T., Giacomoni, J., Gobbi, M., Hamonou, E., Olafsson, H., Dagsson-Waldhauserova, P., Camy-Peyret, C., Mazel, C., Décamps, T., Piringer, M., Surcin, J., and Daugeron, D.: LOAC: a small aerosol optical counter/sizer for ground-based and balloon measurements of the size distribution and nature of atmospheric particles - Part 1: Principle of measurements and instrument evaluation, Atmos. Meas. Tech., 9, 1721-1742, doi:10.5194/amt-9-1721-2016, 2016.

Ravetta, F., Ancellet, G., Kowol-Santen, J., Wilson, R., and Nedeljkovic, D.: Ozone, temperature and wind field measurements in a tropopause fold: comparison with a mesoscale model simulation, Mon. Weather Rev., 127, 2641-2653, 1999.

Rose, S. F., Hobbs, P. V., Locatelli, J. D., and Stoelinga, M. T.: A 10 -yr climatology relating the locations of reported tornadoes to the quadrants of upper-level jet streaks, Weather Forecast., 19, 301-309, 2004.

Schmidt, T., Alexander, P., and de la Torre, A.: Stratospheric gravity wave momentum flux from radio occultations, J. Geophys. Res., 121, 4443-4467, doi:10.1002/2015JD024135, 2016.

Schroeder, S., Preusse, P., Ern, M., and Riese, M.: Gravity waves resolved in ECMWF and measured by SABER, Geophys. Res. Lett., 36, L10805, doi:10.1029/2008GL037054, 2009.

Shapiro, M. A.: Turbulent mixing within tropopause folds as a mechanism for the exchange of chemical constituents between the stratosphere and troposphere, J. Atmos. Sci., 37, 994-1004, 1980.

Shutts, G. J. and Vosper, S. B.: Stratospheric gravity waves revealed in NWP model forecasts, Q. J. Roy. Meteor. Soc., 137, 303-317, doi:10.1002/qj.7, 2011.

Smit, H.: the Panel for the Assessment of Standard Operating Procedures for Ozonesondes (ASOPOS). Quality assurance and quality control for ozone sonde measurements in GAW, GAW Report no. 201, World Meteorological Organization, available at: http://www.wmo.int/pages/prog/arep/gaw/documents/GAW 201.pdf, 2013.

Smit, H., Straeter, W., Johnson, B., Oltmans, S., Davies, J., Tarasick, D., Hoegger, B., Stuebi, R., Schmidlin, F., Northam, T., Thompson, A., Witte, J., Boyd, I., and Posny, F.: Assessment of the performance of ECC-ozonesondes under quasi-flight conditions in the environmental simulation chamber: Insights from the Juelich Ozone Sonde Intercomparison Experiment (JOSIE), J. Geophys. Res., 112, D19306, doi:10.1029/2006JD007308, 2007.

Solomon, S., Daniel, J. S., Neely III, R. R., Vernier, J. P., Dutton, E. G., and Thomason, L. W.: The persistently variable "Background" stratospheric aerosol layer and global climate change, Science, 333, 866-870, doi:10.1126/science.1206027, 2011.
SPARC Report No. 4: SPARC Assessment of Stratospheric Aerosol Properties (ASAP), edited by: Thomason, L. and Peter, Th., WCRP-124, WMO/TD SPARC, 2006.

Spichtinger, P., Gierens, K., and Dörnbrack, A.: Formation of ice supersaturation by mesoscale gravity waves, Atmos. Chem. Phys., 5, 1243-1255, doi:10.5194/acp-5-1243-2005, 2005.

Stohl, A., Wotawa, G., Seibert, P., and Kromp-Kolb, H.: Interpolation errors in wind fields as a function of spatial and temporal resolution and their impact on different types of kinematic trajectories, J. Appl. Meteor., 34, 2149-2165, 1995.

Stohl, A., Forster, C., Frank, A., Seibert, P., and Wotawa, G.: Technical note: The Lagrangian particle dispersion model FLEXPART version 6.2, Atmos. Chem. Phys., 5, 2461-2474, doi:10.5194/acp-5-2461-2005, 2005.

Teitelbaum, H., Ovarlez, J., Kelder, H., and Lott, F.: Some observations of gravity-wave-induced structure in ozone and water vapour during EASOE, Geophys. Res. Lett., 21, 1483-1486, 1994.

Thomas, L., Worthington, R. M., and McDonald, A. J.: Inertiagravity waves in the troposphere and lower stratosphere associated with a jet stream exit region, Ann. Geophys., 17, 115-121, doi:10.1007/s00585-999-0115-4, 1999.

Tsuda, T., Nishida, M., Rocken, C., and Ware, R. H.: A global morphology of gravity wave activity in the stratosphere revealed by the GPS occultation data (GPS/MET), J. Geophys. Res., 105, 7257-7273, 2000.

Uccellini, L.W. and Koch, S. E.: The synoptic setting and possible energy sources for mesoscale wave disturbances, Mon. Weather Rev., 115, 721-729, 1987.

Vaughan, G., Jenkins, D. B., Thomas, L., Wareing, D. P., and Farrington, M.: Dynamical influences on stratospheric aerosols observed at Aberystwyth in early 1983, Tellus, 39B, 398-411, 1987.

Vincent, R. A., Allen, S. J., and Eckermann, S. D.: Gravity wave parameters in the lower stratosphere. Gravity wave processes: Their parameterization in global climate models, Springer-Verlag, 725, 1997.

Walker, J. S.: A Primer on Wavelets and Their Scientific Applications, Chapman \& Hall/CRC Press, 318 pp., 2008.

Wang, L. and Alexander, M. J.: Global Estimates of gravity wave parameters from GPS radio occultation temperature data, J. Geophys. Res., 115, D21122, doi:10.1029/2010JD013860, 2010.

Wang, S., Zhang, F., and Snyder, C.: Generation and propagation of inertia-gravity waves from vortex dipoles and jets, J. Atmos. Sci., 66, 1294-1314, doi:10.1175/2008JAS2830.1, 2009.

Wei, J. and Zhang, F.: Tracking gravity waves in moist baroclinic jet-front systems, J. Adv. Model. Earth Syst., 7, 67-91, doi:10.1002/2014MS000395, 2015.

Xu, J., Smith, A. K., and Brasseur, G.: The effects of gravity waves on distributions of chemically active constituents in the mesopause region, J. Geophys. Res., 105, 26593-26602, doi:10.1029/2000JD900446, 2000.

Zahn, A., Brenninkmeijer, C. A. M., Maiss, M., Scharffe, D. H., Crutzen, P. J., Hermann, M., Heintzenberg, J., Wiedensohler, A., Giisten, H., Heinrich, G., Fischer, H., Cuijpers, J. W. M., and van Velthoven, P. F. J.: Identification of extratropical two-way troposphere-stratosphere mixing based on CARIBIC measurements of $\mathrm{O}_{3}, \mathrm{CO}$, and ultrafine particles, J. Geophys. Res., 105, $1527-1535,2000$. 
Zhang, F.: Generation of mesoscale gravity waves in uppertropospheric jet-front systems, J. Atmos. Sci., 61, 440-457, 2004.

Zhang, S. D., Huang, C. M., Huang, K. M., Yi, F., Zhang, Y. H., Gong, Y., and Gan, Q.: Spatial and seasonal variability of medium- and high-frequency gravity waves in the lower atmosphere revealed by US radiosonde data, Ann. Geophys., 32, 1129-1143, doi:10.5194/angeo-32-1129-2014, 2014. 